\title{
RIQUEZA Y POBREZA DEL CLERO SECULAR EN LA SEVILLA DEL ANTIGUO RÉGIMEN (1700-1834).
}

\author{
LEON CARLOS ÁLVAREZ SANTALÓ \\ ANTONIO GARCÍA-BAQUERO GONZÁLEZ \\ Universidad de Sevilla
}

«De quien pone los ojos en el suelo no fies tu dinero».
"Quien tiene pie de altar come pan sin amasar».
«Ayer entró en la Iglesia y hoy se quiere alzar con toda ella» (1).

Cuando se trabaja con una «muestra» sociológica como la que aquí se utiliza, «garantizada» por la documentación notarial (en este caso la de inventarios post mortem), el prurito estadístico se erige como un fantasma crítico: ¿qué significado conceder a los resultados cuantitativos y cualitativos y qué capacidad de extrapolación a sus cifras? Nuestra opinión al respecto es bien simple y ya reiterada en otras aportaciones similares publicadas (2): nos parece inoportuno y absolutamente ineficaz utilizar la «muestra» como una parte proporcional de «algo» y aplicarle en consecuencia las «leyes» que tejen las proporciones y sus significados (medidas aritméticamente) entre las fracciones y los todos, sus recovecos «legales» (estadísticamente «legales», va de suyo) y sus aparentemente ordenadas relaciones de representatividad matemática. Las distancias que el buen sentido (empírico o no) establece entre la parte (la muestra) y el todo (el clero secular que vivió en Sevilla entre 1700 y 1834) resultan de tal dimensión que una pretensión «matemática» de implicar ambos parámetros en alguna coherencia real parece poco más que surrealismo entusiasta. La cuestión, por lo tanto, no creemos que sea respecto a la «identidad» entre ambos conjuntos ni sobre la eficacia de una proyección «creciente» del menor hacia el mayor, «garantizada» por la geometría de las extrapolaciones; sabemos que este clero no tiene por qué ser El Clero de la ciudad y la época, sino Un clero. De este modo, el fragmento pasa a ser considerado un «todo»; es el que tenemos y lo sometemos a análisis como tal. En qué medida este modelo «construido» se aproxime o maquete al clero histórico, es problema que depende, en parte, de la razonabilidad de las conclusiones y de su capacidad de adaptarse a otras informaciones parciales. A nuestro juicio, el resultado, en promedio, parece bastante verosímil. Hay otro «todo», desde luego, que es el que compone la encuesta total de los 1.882 inventarios valorados para la Sevilla de las mismas fechas; entre ambos sí pueden establecerse relaciones más precisas y porcentuadas, en la medida en que los «males» que afecten a un grupo afectan de igual forma o casi al conjunto de la encuesta y nos parece que ello permite establecer relaciones eficaces y razonables entre los distintos grupos sociológicos entre sí y con la encuesta global. Otro problema, diferente, afecta a la credibilidad de los datos notariales; suele constituir un lugar común mostrar dos clases de desconfianza: la primera, más «sustancial» se apoya en la afirmación, bastante generalizada, de que el inventario, per se, constituye un filtro que «deforma» la realidad social en la medida en que 
«separa» a poseedores y no poseedores, ya que se da por supuesto que solo se inventaría a los primeros; la segunda, probablemente más razonable, se refiere a las carencias, por defectividad, de los datos mismos (ausencia de bienes vinculados, descuido o generalización en la consignación de ciertos bienes, ausencia constatada de otros que se citan pero no se recogen por distintos motivos, etc) (3). La primera que, con cierta probabilidad, parece perjudicarse de alguna contaminación del «elitismo» presumible de otra práctica notarial aparentemente más selectiva como el testamento, no puede decirse que sea corroborada, tal cual, por los datos «reales»; la presencia de inventarios e incluso particiones o almonedas con niveles patrimoniales tan reducidos que apenas alcanzan algunas docenas de reales parece sugerir una prueba en contrario. Desde luego podría arguiirse que, en tales casos, se trata «sin duda» de manifiestas ocultaciones o maniobras económicas «evidentemente» destinadas al camuflaje o a la «estafa» familiar, sin más; tal argumentación resulta cuando menos tan arbitraria y aventurada como su contraria y parece poco demostrable. Ciertamente los conceptos de «tenen» o «no tener», para una sociedad dada, pueden resultar muy relativos, pero parece rizar el rizo dar por sentado que los niveles eficazmente visibles de pobreza absoluta de muchos inventarios «quieren decir», solamente, que el «tener» de kesa» sociedad estaba situado más abajo que en otras; cuando se alcanza el suelo, eso es el suelo. De modo que, en nuestra opinión, el inventario con el que estamos familiarizados resulta más «democrático» de lo que con frecuencia se predica. En parte, las críticas proceden o pueden proceder de las variaciones locales y cronológicas; cada archivo de protocolos, casi, presenta peculiaridades tipológicas que hacen arriesgadas las extrapolaciones y generalizaciones y cada investigador suele conocer «los suyos». Cosa muy diferente resulta la segunda objeción y no existen mayores problemas de verosimilitud en aceptarla. Efectivamente, la presencia de un iventario perfecto es rara avis. Hay carencias, embrollos, anotaciones equívocas y ausencias declaradas, sin contar con ocultaciones interesadas o criterios peculiares de notarios; en qué medida pueda afectar todo ello a la credibilidad de los datos es también, creemos, un problema de sensatez respecto a los objetivos de la investigación. Es bastante dudoso que, con ellos, puedan construirse catedrales aritméticas indiscutibles, pero parece igualmente probable que sí puedan intentarse planimetrías sociovitales bastante eficaces en tanto sintomátivas. Ampliarlas y cruzarlas con otras fuentes es tarea que aconseja el sentido común y el método científico. Tal vez, en un primer momento, el investigador se siente tentado a suponer que con los inventarios en la mano dispone (al menos para aquéllos a los que se refieren) de una radiografía total y cuantificada de patrimonios, deudas, gastos post mortem y, en definitiva, de modos de vida rigurosos y de precisión; en seguida advierte que sólo dispone de parámetros eficaces para establecer tendencias; tendencias de las fortunas, las pobrezas, los niveles de gasto o inversión, tendencias de las distancias «visibles» entre muy ricos, ricos, acomodados, normales, con escaseces, pobres y miserables sin remisión. Por cierto, nada muy diferente de lo que sucede con otros parámetros de la investigación historiográfica. Pensamos, por tanto, que gracias a los inventarios y a sus transparencias «reconocemos» eficazmente la malla social y nos acercamos, desde esa perspectiva, a su cotidianidad; nada 
más...y nada menos. En ese sentido y en muestras de algún relieve, como la que nos ocupa, nos parece que la posibilidad de establecer un cuadro razonable de indicios e hipótesis respecto a las personas es mucho mayor que cualquiera de las generalidades que obligatoriamente se desprenden de aproximaciones institucionales, de las del tipo «el clero era así o así» y no digamos de frecuentes extrapolaciones absolutamente capri-chosas sobre la base de una biografía $o$ unos cuantos ejemplos específicos. Cualquier conclusión,en todo caso,queda como provisional y sujeta a las re-visiones obligadas cuando una documentación más voluminosa y precisa así lo exija.

Por lo que respecta al clero secular sevillano del siglo XVIII disponemos recientemente de excelentes monografías sobre su formación y «trabajo» pastoral (con su correspondiente reverso de irregularidades y conductas censurables) así como estudios institucionales (4), pero no disponemos de ninguna aproximación detallada a sus niveles de riqueza personal y sus fragmentos de vida cotidiana. Ello nos hace suponer que este trabajo no resultará completamente inútil y que pese a lo reducido de la muestra (apenas un centenar y medio de inventarios) podría constituir un, razonablemente eficaz, portillo para vislumbrar «curas» que, como expresaría el habla popular, son «de carne, hueso y pescuezo".

\section{1.-Caracterización básica de la muestra.}

Disponemos de una muestra compuesta por 142 inventarios de clérigos seculares;representan el 7,5\% del total de los 1.882 que constituyen el universo de esta «encuesta» sobre la sociedad sevillana a partir de inventarios post mortem, valorados, entre 1700 y 1834 . No habrá que advertir, ya, que carecería de rigor intentar extraer conclusiones estadísticas del significado porcentual de este segmento con respecto al hipotético conjunto sociológico de la Sevilla de esa época, en el sentido de que un conjunto de inventarios siempre aleatorio reproduzca, cuantitativamente, en escala porcentual, la estructura general de una población dada. Es más, esta advertencia ni siquiera sería precisa si recordamos que, para el periodo cronológico que comprende nuestra encuesta, estamos hablando de una población «constante» anual en torno a las 80.000 personas mientras que sólo disponemos, como acabamos de señalar, de 1.882 inventarios valorados, distribuidos a lo largo de 134 años. Tal desproporción anula evidentemente cualquier intento de encontrar algún esquema de representatividad aritmética conjuta. De este modo, el número de inventarios en cada segmento sociológico, en el mejor de los casos, sólo debe referirse al universo de la encuesta y permitir una aproximación tendencial a las peculiaridades de su status vital, en la medida en que de ellos obtenemos información comparable con las de otros segmentos sociológicos en la misma muestra.

Dicho esto y al objeto de puntualizar el papel de este grupo de inventarios del clero secular respecto a otros sectores de la citada encuesta, habría que empezar señalando que frente al 7,5\% que los mismos representan, el conjunto de los 
comerciantes suponen prácticamente el $29 \%$ de la muestra, los artesanos y fabricantes el $15 \%$ y la nobleza el $5 \%$, por citar los sectores más representativos en un abanico de status; realmente, los valores más próximos a los del clero serían los de los «propietarios agrícolas» con un $8,3 \%$ y los de los funcionarios y las «profesionales liberales» con un 7,9\%. Ahora bien, si en lugar de atender al número de inventarios fijamos nuestra atención en el volumen de sus respectivos capitales, en la medida que parece lógico interesarnos por el peso de algo que pudiésemos entender como la riqueza de este clero secular (en relación con otros segmentos sociales controlados), empezamos a comprender mejor el puesto relativo en el que se encuentra el grupo. En efecto, desde este punto de vista nuestro clero, con 9.928.624 reales de vellón de capital activo, tan sólo cubre el $1,6 \%$ del total del capital inventariado en la encuesta (que asciende a 618.628.100 rs de vellón); para matizar este dato conviene, a su vez, señalar que la nobleza, por ejemplo, acapara prácticamente el $15 \%$ del capital activo inventariado de dicha encuesta, los comerciantes el $54 \%$, los propietarios agrícolas el $8 \%$ y otros grupos, como el integrado conjuntamente por los funcionarios y las profesiones liberales el 6\% (5). Estos datos parecen indicar que el segmento clerical del que nos ocupamos no se incrusta precisamente como grupo en los que pudiésemos considerar elites económicas urbanas, aunque algunos de sus miembros, con seguridad, demuestran formar parte de ellas. A mayor abundamiento, si nos fijamos en el capital medio que puede obtenerse de esta muestra y que para el clero secular significa 69.920 rs.vn. podremos constatar que dicha cifra ocupa el último lugar de los sectores sociales identificados, quedando detrás de él, únicamente, el capital medio del grupo de los «sin especificar» que, por cierto, agrupa al $21 \%$ del total de los inventarios de la encuesta. No solamente eso, el más próximo de los capitales medios que se sitúan por encima del clerical, que es el de los artesanos, sube hasta los cien mil reales largos, marcando así una distancia bien significativa respecto al status aritmético presumible de nuestros clérigos. Como es natural, estos datos no son más que aproximaciones cuantitativas al grupo, dentro del cual, como tendremos ocasión de comprobar, pueden, a su vez, situarse niveles muy distintos. En cualquier caso ya podemos advertir que sólo el $27,5 \%$ de estos inventarios clericales están en o sobre el capital medio, de modo que el $72,5 \%$ restante no lo alcanza. Semejante circunstancia nos va advirtiendo sobre la composición interna del grupo; se marca en él una base muy amplia integrada por los que podríamos considerar como los menos favorecidos y una pequeña cúpula a la que podríamos llamar la «aristocracia» del sector. Esta percepción se matiza aún más si constatamos que ese $27,5 \%$ de la muestra que se sitúa por encima del capital medio acapara el $81,3 \%$ de los activos inventariados y que,en realidad, el $16,2 \%$ de los inventarios, por sí solo, acumula el $75 \%$ de todo el capital. De manera aún más expresiva lo que estas cifras quieren decir es que 23 clérigos, de los 142 inventariados, disponen de las tres cuartas partes de todo el capital del grupo. Esta pirámide, independientemente de su valor estadístico, vuelve a poner de relieve lo que viene resultando una constante del «universo» socioeconómico al que se refiere la encuesta, a saber: cualquiera que sea el segmento estudiado, inmediatamente se detecta una distancia espectacular entre los que «de verdad» poseen y los demás; con toda frecuencia, esta distancia se 
sitúa entre el $10-15 \%$ que constituye la cúpula (y aún menos) y el $90-85 \%$ que representan las bases. En nuestro caso, por ejemplo, los nueve inventarios más fuertes (es decir, el 6,3\% de la muestra) disponen del 50\% del capital inventariado y esa es la verdadera cúpula de la cúpula.

Abandonemos provisionalmente la situación y localización de nuestro clero en el contexto sociológico inventariado y centrémosnos en la profundización de sus niveles de fortuna con cuantas matizaciones sean posibles. En su momento, el programa informático distribuyó el total de los capitales de los 1.882 inventarios en una escala de 16 tramos que abarcaba desde los capitales inferiores a los 1.000 reales, en el primero, hasta los comprendidos entre los 16 y los 32 millones de reales en el último. Pues bien, en esta escala el total de los activos del clero solo cubren los primeros once tramos con la distribución que muestra el cuadro siguiente:

\begin{tabular}{|c|c|c|c|c|}
\hline Dia & 16n invent & $\begin{array}{l}\text { ladro } n^{2} \\
\text { Los clero }\end{array}$ & eecrín nivelee de & activos \\
\hline Niveles & $\mathrm{N}$ Invs. & Tota1 & Activos & \& Total \\
\hline $0-1.000$ & 4 & 2,82 & 2.515 & 0.02 \\
\hline $1-2.000$ & 2 & $1 ; 41$ & 3.438 & 0,03 \\
\hline $2-4.000$ & 10 & 7,04 & 28.507 & 0.29 \\
\hline $4-8.000$ & 22 & 15,49 & 133.968 & 1,35 \\
\hline $8-16.000$ & 23 & 16,20 & 284.179 & 2,86 \\
\hline $16-32.000$ & 22 & 15,49 & 468.531 & 4,72 \\
\hline $32-64.000$ & 20 & $14 ; 08$ & 920.800 & 9,27 \\
\hline $64-128.000$ & 16 & 11,27 & 630.843 & 6,35 \\
\hline $128-256.000$ & 14 & 9,86 & 2.535 .214 & 25,53 \\
\hline $256-512.000$ & 6 & 4,22 & 2.270 .279 & 22,87 \\
\hline $512-1.024 .000$ & 3 & 2,11 & 2.650 .350 & $\underline{26.69}$ \\
\hline & 142 & 100,00 & 9.928 .624 & 100,00 \\
\hline
\end{tabular}

Una mirada, incluso superficial, a este cuadro, parece indicar tres tramos verosímiles de status, en la medida en que estemos dispuestos a establecer una correlación eficaz entre activos inventariados y nivel social: un primer tramo hasta los 8.000 rs. de activo, un segundo desde éstos hasta los 128.000 y un último desde aquí al millón. El primer segmento agrupa a 38 inventarios (el $27 \%$ del sector) que disponen solo del 1,7\% del capital del grupo; el segundo, con 81 inventarios (57\% del grupo) detenta el $23 \%$ del capital y el tercero, con 23 inventarios ( $16 \%$ de la muestra) acumula el $75 \%$. Parece, pues, evidente que esta muestra reproduce, hasta cierto punto, la previsible estratificación genérica de una sociedad de Antiguo Régimen: una cola de «pobreza» evidente, cualquiera que sea el baremo utilizado para medirla (en nuestro caso el más eficaz es que su capital medio apenas alcanza los 4.000 rs., es decir, el $6 \%$ del capital medio del grupo) y que constituye algo más de la cuarta parte; unas «clases medias» que conforman el núcleo sustantivo del sector (recordemos que representan casi el $60 \%$ del total) y cuyo capital medio, en torno a los 28.000 rs., representa sólo el $40 \%$ del capital medio del conjunto; por último, el nivel «rico», poco más del $16 \%$ pero que tiene un capital medio casi cinco veces superior al del conjunto, que abarca, como ya sabemos, tres cuartas partes de todo el capital inventariado y que, como también se ha dicho, dispone de una cúspide que, aunque sólo 
representa el $6 \%$ de los inventarios, dispone, no obstante, del $50 \%$ del capital. Una gradación, pues, no por previsible menos verídica y que «contiene», como una miniatura, la del agrupamiento social general.

Sin ningún ánimo de garantía estadística y sí sólo como una analogía significativa, podemos comprobar esta afirmación sometiéndola al test, incluso equívoco, de comparar el diagrama del clero secular que acabamos de trazar con el que resultaría aplicando criterios similares al total de la encuesta (es decir, a los 1.882 inventarios). El resultado es que encontramos aquí, igualmente, una cúpula (compuesta por la nobleza, los grandes comerciantes y los fabricantes) que conteniendo el $20 \%$ de los inventarios acapara el $65 \%$ del capital; unos grupos de «clases medias» (con pequeños comerciantes, propietarios agrícolas, rentistas urbanos, profesionales liberales, funcionarios y militares) con el $37 \%$ de los inventarios y el 27\% del capital; y una «cola» de pobreza (desde luego con su escala correspondiente y compuesta por los «no identificados», los criados, los artesanos y el clero mismo) que con el $43 \%$ de los inventarios sólo alcanza el $8 \%$ del capital total inventariado. Si se comparan ambos diagramas (sin más intención que la comparación misma) podemos darnos cuenta de la proximidad de los porcentajes resultantes. Probablemente no tiene mucho sentido ahondar en este paralelismo aunque podría llevarse algo más lejos; por ejemplo y de paso, se puede señalar que la «cola» de pobreza (sin llegar a miseria) del diagrama general apenas alcanza un capital medio que representa el $19 \%$ del capital medio del total de la encuesta; que las «clases medias» de este diagrama general disponen de un capital medio que, con dificultad, se aproxima a las tres cuartas partes del general y que la cúpula, por el contrario, atestigua un capital medio que multiplica por tres, con largueza, el del conjunto. El sentido analógico de ambos diagramas parece bastante verosímil y, en ese sentido, eficaz y corrobora la tesis comúnmente sostenida de que el clero secular no dispone de una peculiaridad socioeconómica propia o diferenciada y que tiende a reproducir el esquema común del conjunto social (6).

Una vez pasada revista a los activos vamos a matizar y completar esa información, como prometimos, refiriéndonos a los pasivos de todo tipo que constituyen una merma empírica de los capitales inventariados. De entrada, tal merma se concreta en 1.863 .540 rs. que equivalen al $19 \%$ del total del capital clerical inventariado; estos pasivos aparecen únicamente en 50 de los 142 inventarios que controlamos (por tanto, $35,2 \%$ de la muestra). La tipología de tales pasivos contiene tres rúbricas: las deudas en contra que suman 1.364 .890 rs. distribuidos en 43 inventarios; los censos y tributos con que está gravado parte del capital inmobiliario que ascienden a 303.217 rs. repartidos en 5 inventarios y de los que 249.529 corresponden a censos y 53.688 son tributos; por último, el conjunto de gastos post mortem (funeral, honras, mandas pías y legados) que suman 195.433 rs. recogidos en 21 inventarios. Como puede fácilmente comprobarse, tanto por su cuantía (73,2\% del valor total del pasivo) como por su frecuencia de aparición (86\% del total de los inventarios que consignan pasivos), las deudas en contra se erigen en protagonistas indiscutibles de las cargas que gravan los capitales del grupo. Como sucederá con otras 
rúbricas la frecuencia de su aparición en los inventarios resulta engañosa; podemos clarificar la situación al señalar que solo 9 de los 43 inventarios que tienen deudas acumulan 1.015.255 rs., es decir prácticamente el $75 \%$ de toda la rúbrica, de modo que son estos inventarios los responsables efectivos del volumen acumulado.

\section{2.-El organigrama del capital activo.}

Centrándonos ahora en el organigrama económico de nuestro clero secular, una primera aproximación al respecto puede quedar sintetizada en el cuadro adjunto en el que se recoge la distribución del capital en bienes muebles e inmuebles, ordenados, a su vez, según la escala de activos que ya conocemos:

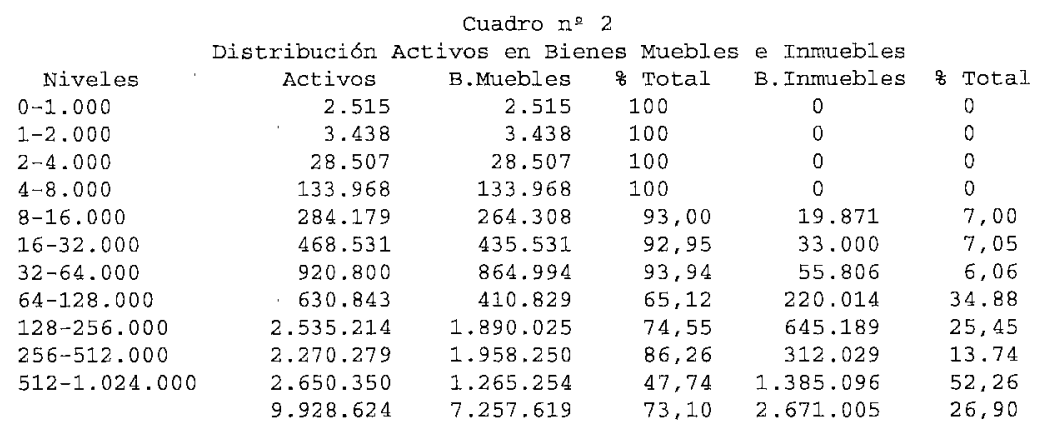

La conclusión más inmediata es que la existencia de bienes inmuebles sólo aparece en los tramos superiores y solo resulta verdaderamente importante en los más altos (la cúspide de la cúpula). Nada sorprendente, por cierto, como tampoco debería serlo que no se produzca una escala cuantitativa aritméticamente perfecta; tratando con inventarios, la presencia o no de bienes inmuebles resulta siempre más susceptible de defectividad y, en cualquier caso, en esos tramos de la escala se sitúan ya un número de inventarios lo suficientemente corto como para producir oscilaciones numéricas que pueden deberse a la presencia de un solo inventario distorsionador. En líneas generales la tendencia es bastante clara: hasta los 8.000 rs. de activo éste resulta idéntico al valor de los bienes muebles y no existen, por tanto, inmuebles; entre los 8.000 y los 64.000 rs. los bienes inmuebles hacen acto de presencia aunque su valor proporcional no supera el $7 \%$ de los activos; a estas alturas han quedado integrados ya el $72,5 \%$ de los inventarios de la muestra, de modo que parece bastante claro que tres cuartas partes de esta muestra o no poseen bienes inmuebles o los que tienen apenas representan algo en los patrimonios. A partir de los 64.000 rs. el volumen de los inmuebles y su peso proporcional crecen notablemente (aunque con «tirones» desiguales) hasta alcanzar en la cúspide, algo más del $50 \%$ del total de los activos aunque esta cúspide solo contiene tres inventarios. La distancia de «riqueza» que los separa de los cuatro inventarios del tramo más bajo es inmensa (2.500 rs. en estos, 2.650 .000 en aquellos) y también lo es, evidentemente, la presencia y el valor de sus inmuebles (cero en 
estos y casi millón y medio en aquellos). Que esta distancia dibuje, casi, una caricatura aberrante no quiere decir que resulte inverosímil sino, más bien, que este tipo de distancia en las sociedades del Antiguo Régimen establecen siempre, un diagrama que parece surgido de una pesadilla satítica (7).

La impresión general que proporcionan, así, los datos, es la de un clero modesto en su inmensa mayoría, que concentra su patrimonio en el habitat doméstico y con una punta de pirámide que puede asociarse ya con clases urbanas de mayor enjunđia económica; pero esta impresión general debemos someterla ahora a un doble contraste: la pormenorización de los bienes muebles e inmuebles en un diagrama conjunto de toda la muestra y su fraccionamiento comparativo en bloques que, con toda prudencia, pudiéramos denominar «sociológicos» o de status socioprofesional.

Comenzaremos, pues, por la primera opción. Como es natural, su expresión más clara se refleja en el siguiente cuadro que constituirá el campo de análisis inmediato.

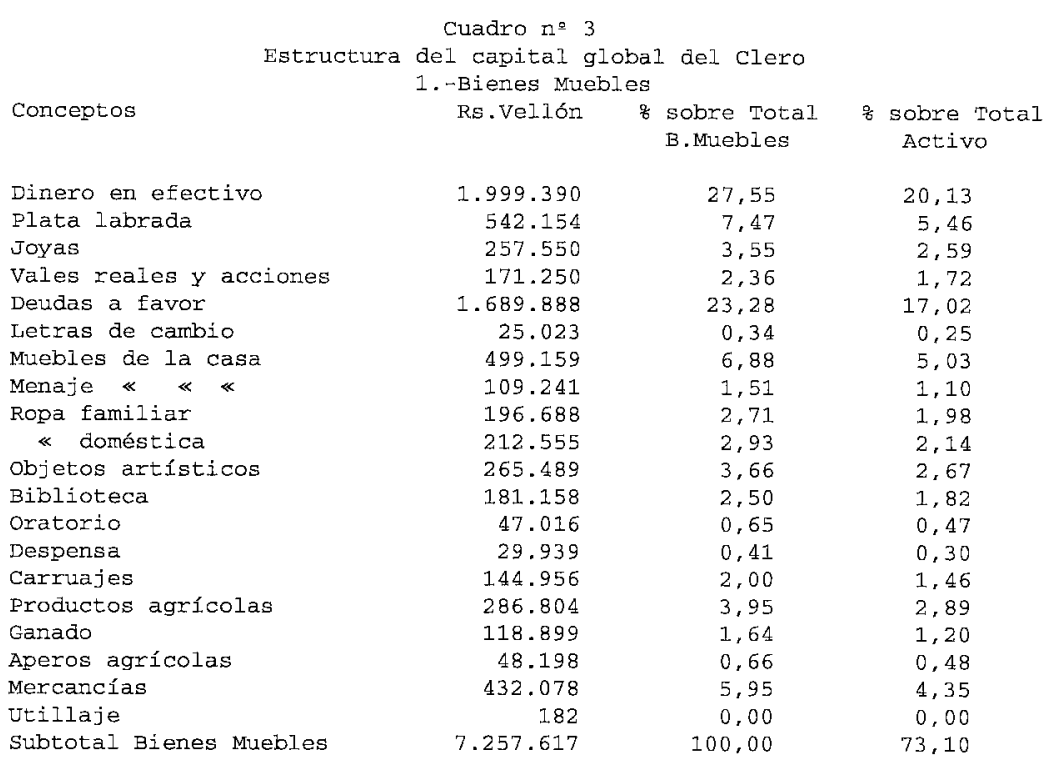

2.-Bienes Inmuebles

\begin{tabular}{|c|c|c|c|}
\hline $\begin{array}{l}\text { Conceptos } \\
\text { B.Inmuebles Activo }\end{array}$ & Rs.Vellón & a sobre Total & sobre \\
\hline Tierras & 234.486 & 8,78 & 2,35 \\
\hline Edificaciones rústicas & 89.233 & 3,34 & 0,90 \\
\hline Inmuebles urbanos (casas) & 2.089 .214 & 78,22 & 21,04 \\
\hline Locales de negocios & 44.702 & 1,67 & 0,45 \\
\hline Censos $y$ ofictos venales & 213.370 & 7,99 & 2,15 \\
\hline Subtotal Bienes Inmuebles & 2.671 .005 & 100,00 & 26,90 \\
\hline
\end{tabular}


Comenzaremos el análisis por los bienes muebles y por una variable harto significativa: la frecuencia de aparición de cada una de las rúbricas en los distintos inventarios. Independientemente de los valores que estos desgloses acumulan, su frecuencia responde, con la mayor probabilidad, a lo que podríamos considerar como una primera garantía de la «veracidad» sociovital de la inversión que representan. Efectivamente, hay conceptos que, con toda claridad, apuntan a una presencia masiva y que está referida a su peso en la vida cotidiana y el cotidiano habitat. Evidentemente la rúbrica más común es la que se refiere a los muebles y el menaje de la casa; aparece en 136 inventarios en el primer caso y en 113 en el segundo. A continuación, como era de esperar, las rúbricas de la ropa personal y la de uso doméstico; la primera se consigna en 127 inventarios y la segunda en 108. En tercer lugar y completando lo que hemos llamado el área de la vida cotidiana, aparecen los objetos de decoración o artísticos y los libros; los primeros están presentes en 119 inventarios y los segundos en 110. Como matización a este último grupo conviene tener en cuenta un «elemento» sin duda excepcional pero del mismo tenor, a saber, los oratorios privados que solo se incluyen en 15 inventarios. Finalmente, el área de la vida común debería completarse con dos rúbricas más, las despensas y los carruajes; las primeras constan en 18 inventarios y los segundos en 26. Esta simple distribución «confirma» el perfil que los datos generales han ido apuntando pues si,como era previsible, muebles, ropa y menaje son patrimonio constante, en cambio oratorios, coches y despensas (porque previsiblemente sólo serán objeto de inventario las de cierta entidad) parecen marcar con algún descaro la minoría «que tiene»; por cierto, la constancia de la presencia de objetos de arte y libros sugiere también, una especie de tipificación del grupo respecto a otros segmentos sociales.

Un segundo bloque de bienes, que tambiên forman parte del habitat doméstico aunque en un rango que podríamos llamar, sin excesivo rigor, «suntuario», estaría compuesto por la plata labrada y las joyas. La primera aparece en 89 inventarios (lo que, por cierto, confirma la relativa cotidianidad de su presencia) y las segundas en 55. De todos modos, son éstas rúbricas que en mayor medida que otras requieren de una matización cuantitativa (que después veremos) para comprender su verdadero sentido.

Un tercer bloque podrían integrarlo aquellas rúbricas con un sentido claramente referido a la actividad económica y que están en directa relación con los ingresos tanto de su status clerical como de cualquier otra dedicación «mundanal» simultánea (y ya veremos que hay casos probatorios en este sentido) desarrollada por nuestros clérigos. Las rúbricas en cuestión serían: el dinero en metálico (evidentemente aquí en su acepción plena), los vales reales y las acciones, las deudas a favor, las letras de cambio, los productos agrícolas, el ganado, los aperos de labranza, las mercancías y el utillaje. La frecuencia respectiva de cada resulta reveladora de su peso específico relativo en la «actividad económica» de los inventariados: el dinero figura en 75 inventarios, las deudas en 61 , los productos agrícolas en 35 , el ganado en 13 , los aperos en 10 , 
los vales y acciones en cuatro, las mercancías en tres, el utillaje en dos y las letras de cambio en uno.

Por lo que se refiere, a su vez, a los bienes inmuebles,su desglose también resultará útil para una primera «definición» del estilo de vida del grupo: en primer termino y como era de esperar se sitúan las casa que aparecen en 29 inventarios; le siguen las propiedades rústicas en 10; a continuación, los censos y oficios venales que se reseñan en seis inventarios y, cerrando la relación, las edificaciones rústicas con presencia en cuatro inventarios y los locales de negocios en tres.

Si tuviésemos que establecer un «diagnóstico sociológico» del grupo atendiendo exclusivamente a este parámetro de la frecuencia con que cada «bien» aparece en la muestra estadística, parece evidente: que estaríamos en presencia de «vidas» cerradas en el espacio domiciliar, en las que la propiedad inmobiliaria es poco más que testimonial y, en cualquier caso, siempre sobre el inmueble urbano que no el rústico; que aflora un gusto por el ornato y la lectura muy por encima de una plausible media social (más de un $75 \%$ de los inventarios poseen libros y casi un $80 \%$ objetos artísticos); que se manifiesta una muy frecuente capacidad de «atesorar» dinero y metal precioso (aunque bien es verdad que, en el caso del metal precioso, la inmensa mayoría se refiere a vajillas y otros útiles de uso doméstico); que aparece un no menos llamativo «capítulo» de deudas favorables (afecta al $43 \%$ del conjunto) y un, escaso aunque muy comprensible, pequeño grupo de poseedores de productos agrícolas que sugieren jirones de rentas de capellanías y beneficios (una cuarta parte de inventarios los tienen). Lo demás son apuntes significativos pero no decisivos: ese $18 \%$ que poseen carruajes; el $7 \%$ con propiedades rústicas; esos muy escasos propietarios de censos y oficios venales o de vales reales y acciones, excepciones llamativas.

Pero este esqueleto en esbozo puede y debe rellenarse, como ya anunciamos, con la valoración cuantitativa de cada rúbrica que nos proporcionará un significado más fiable de estas primeras impresiones. Comenzaremos por la parte del león que, como ya sabemos, viene constituida por los bienes muebles.

La primera constancia, verdaderamente espectacular, es que sólo dos partidas se erigen como las auténticas protagonistas del valor de estos bienes muebles: el dinero en metálico, que representa el $27,5 \%$ del total y las deudas favorables, que constituyen el $23,3 \%$; entre ambas, por lo tanto, suman el $51 \%$ del total de los bienes muebles y el $37 \%$ del activo del grupo. Su presencia requiere un comentario. En primer lugar es bastante probable establecer una relación nada arbitraria entre ambas presencias, su frecuencia y su valor; se trata de una plausible «complicidad» entre la liquidez y las deudas favorables y ambas apuntan en una dirección harto verosímil: actividades de préstamo. Desde luego no estamos sugiriendo un «negocio» constante y de envergadura pero sí una especie de «monti», personalizados, para círculos de conocidos o de feligreses (con más probabilidad mujeres que dejan alguna «prenda» a cambio del 
préstamo). Por supuesto, la mera presencia de estas rúbricas no puede considerarse como una prueba irrefutable de tal actividad pero, probablemente, sî se aproxima a una más segura confirmación de la hipótesis el peso específico del valor que acumulan; entre esas deudas, con toda seguridad, hay rentas beneficiales, no cobradas e incluso (como nos consta) algún salario de oficio capitular adeudado; algo parecido podría decirse del monto del dinero en metálico, que puede contener «pagos» de actividades del propio sector y resultas de ventas de productos agrícolas decimales o de capellanías. Pero tendremos que reconocer que su volumen y valor relativo resulta, efectivamente, desproporcionado y que apunta (en un porcentaje que evidentemente no abarcará el $100 \%$ de las partidas, pero que podrá intuirse como significativo) a una actividad «complementaria» de préstamo que, en el mejor de los casos, incluso podría considerarse como «característico» del grupo en el sentido de asumir un «servicio» a la comunidad que, difícilmente o muy gravosamente, podría tener acceso a un préstamo de otra procedencia. A este respecto no se debe olvidar que algunas de las joyas reseñadas resultan ser «prendas» como de hecho nos consta, al menos en algún inventario (8).

Al margen de estas dos partidas protagonistas, las que hemos considerado anteriormente como las constitutivas del habitat doméstico neto (muebles, menaje, ropas, despensa, carruajes, objetos artísticos y bibliotecas), agrupados representan el $23 \%$ del valor de los bienes muebles y el $17 \%$ del activo total, es decir, que todos los «bienes del vivir» apenas valen la mitad que el dinero y las deudas favorables. Desagregando, de todas formas el conjunto, sobresalen como partidas más representativas: desde luego el mobiliario en su conjunto (el $8,4 \%$ del valor de los bienes muebles); los que podemos considerar como «bienes culturales» (arte y libros con el 6,8\%) y las ropas con el ajuar doméstico $(5,6 \%)$. A partir de aquí quedan dos partidas de peso similar: por una parte, la plata labrada y las joyas que juntas representan un $11 \%$ del total de los bienes muebles y un $8 \%$ del activo global y, por otra, el conjunto de los bienes de referente agrícola (productos del campo, ganado y aperos) y las «mercancías» (que aunque solo aparecen en tres inventarios representan, aún así, la mitad del valor total de este conjunto) que, a su vez, constituye el $12 \%$ del valor de los bienes muebles y el $9 \%$ del activo total. Finalmente «coronan» este primer conjunto de bienes, sendas partidas de frecuencia testimonial (como las mercancías) pero de significado interesante por su sentido financiero: los vales reales y las «acciones» que equivalen al $2,4 \%$ de los bienes muebles y al $1,7 \%$ del activo.

Si efectuamos ahora un desglose semejante de los bienes inmuebles observaremos que, dentro de su escasez relativa que ya hemos señalado (el conjunto apenas alcanza a representar el $26 \%$ del activo), los inmuebles urbanos acaparan el $80 \%$ del valor total de todos los bienes inmuebles y el $21 \%$ del activo (advirtiendo que los locales de negocio solo constituyen el 1,7\% y el 0,45\% de estos valores), la tierra y los inmuebles rústicos el $12 \%$ de los inmuebles y el $3,2 \%$ del activo y, por último, los censos a favor y los oficios venales el $8 \%$ de los primeros y el $2 \%$ de los segundos. Como puede comprobarse cualquier comentario de estas cifras es una pura obviedad. El protagonismo absoluto del 
inmueble urbano «garantiza» el perfil que venimos proponiendo: un buen pasar, a veces con alguna holgura, a veces ni eso, se corresponde bastante razonablemente con el hecho de una inversión «segura» y que, además, no exija atención excesiva; cuando sobra para invertir, el inmueble urbano satisface ambas apetencias como, en su caso, también lo hacía la actividad prestamista. Desde luego siempre encontraremos algunas excepciones que reflejen actividades comerciales de buen nivel o propiedad agrícola de alguna consideración. Ya llegaremos a ello.

¿Qué podemos precisar detrás de la frialdad de estos porcentajes? En primer lugar deberemos «corregir» la impresión inicial que obteníamos de la cuantificación general y la frecuencia, penetrando en la realidad individualizada de los distintos inventarios que nos permitirá zafarnos de la demasiado evidente apariencia que los promedios aritméticos imponen. Lo haremos precisamente con las dos partidas o rúbricas que tanto nos han llamado la atención y sobre las que, intencionadamente, hemos hecho recaer incluso la responsabilidad de sugerir un cierto perfil de actividades económicas no por atípicas menos sugestivas. Pues bien, cuando nos desentendemos de los promedios y los volúmenes generales de la cuantificación, detectamos otra realidad que matiza decisivamente tales perfiles. En efecto, cuando se desciende al detalle pormenorizado de los inventarios nos encontramos que aquellas dos rúbricas espectaculares y que «parecían» condicionar la conducta de todo el grupo se descomponen en los siguientes aspectos: de los dos millones de reales inventariados bajo el epígrafe de «dinero en efectivo», el $75 \%$, es decir, 1.504.029 rs.vn., lo aportan solamente doce inventarios (el 16\% del conjunto de 75 inventarios que consignan esta partida); a su vez, del casi millón setecientos mil reales que sumaban las «deudas favorables» del grupo, recogidas en 61 inventarios, 1.188 .422 rs.(70\%) corresponden a tan solo ocho inventarios (el $13 \%$ de los que incluyen este concepto). El perfil que emerge ahora nos parece más verosímil y más realista: en «realidad» el dinero en efectivo está acumulado en el $8 \%$ de todo el clero inventariado y las «deudas favorables» en el 6\%. La sensación de pirámide se intensifica y la de una falta de "personalidad» socieconómica del sector también; el status clerical secular no garantiza, con toda probabilidad, un régimen de vida y un status económico; por el contrario, la riqueza y la pobreza lo recorren como al conjunto social, estableciendo dentro del sector las categorías y niveles que corresponden a su presencia e intensidad. Volveremos después sobre eso, pero antes de abandonar estas rúbricas quizás podamos puntualizar algo más respecto, justamente, de los indicios de una actividad prestamista que habíamos situado sobre la correlación de ambas partidas y sobre su frecuencia y volumen; en este sentido parece razonable recomponer ahora la hipótesis sobre la base de aplicar tal actividad a esta minoría verdaderamente rica (con algún añadido de los niveles más altos de los escalones medios). En efecto, de los doce inventarios, ya aludidos, que acumulan el $75 \%$ del dinero en efectivo del grupo, diez corresponden a los tramos más altos que líneas atrás denominábamos en broma «la cúpula de la cúpula»; y por lo que se refiere a las deudas favorables, de los ocho reseñados que acumulaban el $70 \%$ del total de tales deudas, siete se integran en los mismos 
tramos de capital activo que los que acabamos de citar para el dinero; a su vez, de estos veinte inventarios acaparadores de dinero y deudas favorables, cuatro están en ambas rúbricas como protagonistas (es decir corresponden a la cúspide del dinero y de las deudas favorables). Para avalar más aún la hipótesis puede resultar útil acercarnos a las cantidades individualizadas que estas partidas representan porque no es lo mismo hablar de «mucho dinero» que citar cantidades y establecer su significado. Pues bien, de los doce inventarios que más dinero acumulan; uno tiene 313.404 rs. y otro 168.831 rs.; seis se mueven entre $100-150.000 \mathrm{rs}$ y cuatro entre $45-75.000 \mathrm{rs}(9)$. Si recordamos ahora datos sobre el capital medio ( 70.000 rs. escasos), o diferentes valores de la época (una gran casa puede alcanzar un valor entre $40-75.000$ rs. y un verdadero palacio entre 100-150.000 rs; una finca de regadío, con huerta, pozo, alberca y caserío 60.000 rs; el sueldo de un músico de la capilla real 17.500 rs. anuales, etc), podemos hacernos una idea de lo que esas cantidades de dinero representan y de la justificación que necesitarían en cualquier otra hipótesis distinta de la más plausible del préstamo. Porque el monto de las deudas favorables no desdice en absoluto de estas cifras; de los ocho inventarios estrellas en este aspecto, uno tiene como tales 256.764 rs., tres entre 170-180.000 rs., dos entre 100-120.000 rs. y dos entre 80-90.000 rs. Desde luego sería interesante comprobar si estas cantidades de dinero y deudas disponen de alguna justificación precisa; pues bien, de los 15 inventarios de la cúspide a que nos venimos refiriendo, dos sí la tienen de una forma expresa. En efecto, dos miembros de este clero disponen de «coartada» comercial: uno de ellos tiene una tienda con un hermano (es el de las deudas favorables por $256.764 \mathrm{rs}$ ) aunque solo tiene en dinero en efectivo algo más de 16.000 rs; el otro comercia en hierro (es el de deudas a favor por 127.870 rs. y dinero en efectivo por $120.360 \mathrm{rs}$ ). Los otros trece no ofrecen ninguna información expresa de algún tipo de actividad económica que pudiese justificar sus importantes sumas de dinero en efectivo, deudas o ambas. Por consiguiente, parece bastante razonable suponer que el préstamo resulta la más plausible, al menos para este grupo de clero, rico con toda evidencia; el resto, salvo algunas pequeñas muestras de los escalones inmediatamente inferiores a la cúpula, no da señal alguna de poder dedicarse eficazmente a tales tratos.

En segundo lugar de esta revisión cualitativa podemos centrarnos en la partida estrella de los bienes inmuebles: las casas. Su importancia no radica, pensamos, en los valores cuantitativos (pese a que tal rúbrica acapara, como se recordará, el $78 \%$ del total de los bienes inmuebles y el $21 \%$ de todo el capital activo) sino en su significado general para la comprensión del status del grupo y su nivel de vida; de este modo no solamente debe ser valorada su presencia sino, igualmente, su ausencia. Es por eso por lo que, de modo excepcional, se incluye su presencia incluso en los casos en que no aparece valorada en el inventario; tal circunstancia se produce en seis casos de los 29 inventarios que hacen constar esta propiedad, así que el resto del análisis tenemos que hacerlo sobre esos 23 inventarios restantes que tienen casas y las tienen valoradas.

Que de 142 clérigos solo tengan casa propia 29 (prescindiendo ahora de que tengan una o más) parece un elemento de definición sociológica del grupo nada 
despreciable; desde luego, más adelante, tendremos ocasión de definir, con mayor precisión este punto, atendiendo a los matices de subdivisión social que hemos utilizado para su mejor matización, pero ahora el mero hecho numérico sugiere ya una confirmación de algo que pudiésemos asimilar a un nivel de vida mayoritario y que viene dibujándose desde el principio. El dato llamativo, por tanto, es que sólo el $20 \%$ de estos clérigos dispongan de casa propia; si comparamos este parámetro con el bloque artesanal sevillano para la misma época, por ejemplo, encontramos que el $40 \%$ de los artesanos disponían de vivienda propia. La situación, pues, parece indicar que un núcleo mayoritario de estos clérigos podría disponer de vivienda ad hoc, digamos «institucionales» (como párrocos capellanes, prebendados, etc que podrían residir en casas adscritas al lugar de su ministerio) sin que podamos descartar que el monto de capital inventariado de la mayoría (recordemos que el $25 \%$ de la muestra sólo alcanzaba un capital medio de 4.000 rs. y un $60 \%$ apenas llegaba a $28.000 \mathrm{rs}$ ) no resultaba suficientemente holgado como para incluir propiedad inmobiliaria. Se ve más claro si advertimos que los 83 inventarios de menor capital (y eso representa casi el $60 \%$ del total) disponen de un capital medio de 11.000 rs. y que, como era de esperar, solo cinco de ellos tienen casa en el inventario. En definitiva, la frecuencia de aparición de estos inmuebles en el conjunto (salvo que toda la muestra esté viciada de base) parece una prueba más de que los niveles mayoritarios del clero secular podrían haberse desenvuelto en modos de vida muy discretos, cerca e incluso por debajo de una buena parte de los artesanos. Naturalmente en los estratos superiores las cosas son de muy otra forma; un vistazo a los propietarios de casas y la valoración de estas mismas nos aclarará los matices.

De los 23 propietarios de casas valoradas, doce, algo más de la mitad, poseen solamente aquélla en la que viven; tres poseen dos casas; dos tienen tres y los seis restantes, cuatro, seis, siete, ocho, once y cuarenta y seis, respectivamente. Es decir, en realidad, solo el $8 \%$ del total de los clérigos que integran la muestra está en condiciones de utilizar la propiedad de una casa o varias como fuente de rentas aunque, como evidencian las cifras, con muy diversa intensidad. El caso más llamativo, desde luego, lo constituye ese presbítero que acumula 46 casas (el $43 \%$ de todas las inventariadas) con un valor de 901.941 rs que equivale a un porcentaje idéntico del valor total de esta rúbrica. Naturalmente los datos del inventario no siempre responden a nuestra curiosidad o nuestras necesidades; por ejemplo, sólo disponemos de la precisión del valor de las «casas de morada» (cuando se inventarian varias) en tres casos que, junto a los doce que solo poseen su propia vivienda nos da quince oportunidades de penetrar en el status de la vivienda propia. Lo que obtenemos entonces es que cuatro de ellas se valoran por debajo de los 4.000 rs (muy modestas por lo tanto); otras cuatro lo hacen entre 10-25.000 rs (una vivienda digna y holgada aunque no lujosa); a partir de aquí ya estamos en un nivel de casas importantes (por lo que podemos colegir a partir de la información total de la encuesta de los 1.882 inventarios): cinco de ellas se valoran entre $35-70.000$ rs. y las otras dos en 132.000 y 138.596 rs (estas son ya verdaderas casas-palacio). Desde luego estas dos últimas pueden considerarse excepcionales y su relación con sus respectivos capitales activos 
nos señala, también, dos circunstancias bien distintas: en el primer caso, el valor de la casa representa el $80 \%$ de todo su activo, de modo que no hay correlación entre este «bien» y el resto de su patrimonio aunque, es verdad, todo él es equipamiento de la propia casa; en el segundo, por el contrario; la casa (pese a ser la de valor más alto de toda la muestra), solo alcanza a representar e1 $19 \%$ del activo de su dueño, que es, por cierto, el segundo más alto de toda la muestra clerical, porque partidas como su dinero, sus deudas o sus mercancías constituyen también valores muy fuertes. Arriesgando una interpretación de esta diversidad se intuye que, en el primer caso, se trata de una herencia de una buena familia que el clérigo disfruta y que queda muy por encima de un nivel de vida en todo lo demás bien modesto; en el segundo, en cambio, la casa parece absolutamente acorde con su «actividad» y modus vivendi. Por lo que respecta al resto de estas viviendas particulares, la relación entre su valor y el del total del patrimonio se establece con normalidad: son trece; en cinco su valor oscila entre el $50 \%$ y el $82 \%$ del activo; en seis, se sitúa en torno al $21 \%$ y en dos en el $10 \%$ y el $2 \%$ respectivamente. Por cierto, en este último caso, se trata de un canónigo cuya casa se valora en 2.500 rs. pero que tiene una finca rústica con un caserío que se valora en 31.700 rs. y que tiene todas las trazas de constituir su «verdadera» vivienda.

Vayamos ahora a examinar, muy brevemente ya, el conjunto de quienes poseen más de una casa. Son once inventarios como ya sabemos y el valor que esas casas representan en sus respectivos patrimonios resulta ya claramente significativo de su carácter de fuente de ingresos; en efecto, solo en una ocasión su valor alcanza únicamente el $20 \%$ del activo; en cuatro casos este valor oscila entre un $40 \%$ y un $55 \%$ del capital activo; en otros cuatro está por encima del $70 \%$, con holgura,y en dos casos se sitúa en el $90 \%$ largo. El peso de su carácter de fuente de renta se hace notar.

\section{3.-Pormenor y ejemplaridad del modus vivendi.}

Continuando con el tono de matizaciones sucesivas en que nos estamos moviendo, podríamos adentrarnos ahora en estas viviendas y observar, con algún mayor detalle, otras partidas de los bienes muebles inventariados que nos ayuden a darle un poco de músculo a la aritmética, ya que, como bien asegura un refrán normando (citado alguna vez por Le Roy Ladurie): «cuando los huesos están bien colocados la carne nunca queda mal encima».

En realidad una «verdadera» anatomía cualitativa que fuera pormenorizando con jugosidad cada una de las partidas, reconvirtiendo el valor monetario en objetos concretos y precisos, convertiría este artículo en un, al menos, medio libro, lo que resulta a todas luces imposible; se trata, por lo tanto, más precisamente de abrir un ojo de cerradura por el que atisbar algunas de las peculiaridades «sugestivas» del interior vital de los habitats clericales. Desde luego puede comprenderse que las rúbricas más habituales y abundantes, muebles, menaje y ropa (familiar y del uso de la casa), no serán los que atraigan nuestra atención, tanto por resultar comunes con otros segmentos sociales como 
por su digamos falta de «personalidad» representativa del grupo clerical, aunque no dejaremos de reseñar algún ajuar llamativo. Otros aspectos parecen más favorables para tomar el pulso cotidiano al grupo; en conjunto, los objetos artísticos (de decoración o uso) y los libros. En efecto, son éstos los bienes que dan al sector clerical su «tono» de vida. Antes de cualquier matización resultará útil contrastar numéricamente esta afirmación. Veamos: de los 142 inventarios del clero con los que trabajamos, 119 tienen «obras de arte» y 110 bibliotecas (más realista sería decir simplemente libros), es decir que el $84 \%$ en un caso y el $77 \%$ en otro se «adornan» con tales bienes. Si ponemos estas cifras en relación con sus análogas en otros segmentos sociales apreciamos que, por lo que al «arte» se refiere sólo la nobleza, con el $81 \%$ de sus inventarios cubriendo esta rúbrica y los funcionarios con el $71 \%$, se aproximan al clero,mientras que el resto queda aproximadamente un $50 \%$ por debajo (así en los grandes comerciantes el «arte» solo aparece en $51 \%$ de sus inventarios, en los pequeños comerciantes en el $42 \%$, en las profesiones liberales en el $55 \%$ y en los artesanos en el 58\%). Si nos referimos a los «libros» la distancia se amplia hasta casi el surrealismo: sólo figuran en el 35\% de los inventarios nobiliarios, en el $22 \%$ de los de los grandes comerciantes, en el $9 \%$ de los pequeños, en el $12 \%$ de los artesanos y sólo en las profesiones liberales y los funcionarios los porcentajes suben hasta el $49 \%$ y el $41 \%$ respectivamente. Podemos afianzar aún más la situación que dibuja la frecuencia de ambas rúbricas en los inventarios, si atendemos al valor proporcional que los susodichos manifiestan con respecto al valor total de los bienes muebles. En el caso del clero, como ya sabemos, los objetos artísticos representan el 3,6\% de tal valor y los libros el 2,5\%; ambas partidas, en la nobleza significan el $0,9 \%$ y el $0,1 \%$ respectivamente; en los grandes comerciantes el $0,3 \%$ y el $0,04 \%$ y en los pequeños el 0,9 y el $0,1 \%$; en las profesiones liberales el $1,6 \%$ y el $1,8 \%$ y en los funcionarios el $1 \%$ y el $0,6 \%$. Es decir que, en el mejor de los casos, el de las profesiones liberales, lo que representan sus libros en función de sus bienes muebles solo alcanza al $72 \%$ del nivel del clero y en cuanto a los objetos artísticos apenas al $44 \%$. En el resto de los sectores sociales las diferencias (por un motivo u otro, no hace ahora al caso) son enormes: respecto a libros y salvando a los funcionarios (para quienes representan aún una cuarta parte del valor proporcional que tenían los del clero) nos movemos en porcentajes del orden del 2 al $4 \%$ de los valores clericales; y en cuanto a los objetos artísticos, entre el 8 y el 25\%. En definitiva, creemos que puede y debe aceptarse que tanto por la constancia de su presencia como por el valor proporcional que representan respecto al capital mueble, ambos conceptos constituyen el toque de peculiaridad cultural del clero respecto al resto del «universo» social de la encuesta y que se justifica la atención pormenorizada (aunque aquí forzosamente habrá de ser breve) que le dediquemos.

Profundizar algo más en estas rúbricas, sin desmesurar el texto con «injertos» excesivos parece posible con algunas muestras «medias». Ya sabemos, por ejemplo, que los 110 inventarios que tienen libros los valoran, en total, en 181.158 rs., es decir, un valor medio de 1.647 rs. que, en promedio, pueden suponer entre 40 y 50 ejemplares; naturalmente la realidad pormenorizada es muy heterogénea y puede ir desde el presbítero «veintenero» D. Francisco 
Bernal de Estrada que solo tiene «un breviario y un diurno» por valor de 20 rs: a los 224 títulos del canónigo D.José Ramón de Aldana que se valoran en 15.306 rs. o los 565 volúmenes del presbítero D.Juan José Llañez tasados en 23.711 rs., pasando por los 90 títulos del cura del Hospital de San Lázaro, D.Jerónimo de Fuertes y Monroy que valen 4.754 rs., los 43 libros que tiene el canónigo D. José Rodríguez Bravo (1.064 rs), los 36 del canónigo D.Manuel González de Aguilar y Rojas (912 rs:) o los 21 del presbítero colector de la capilla de la Antigua D. José Zurita (252 rs.). Para ser precisos, la distribución «real» de estas «bibliotecas» del clero secular es la siguiente: hay cuatro no valoradas, de las otras 106, diez están por debajo de los 50 rs.; cinco, entre 50 y 100 rs. y ocho más hasta los 200 rs.; luego se establece un grupo «ancho» de cincuenta y cinco bibliotecas entre 200 y 1.600 rs.; otro escalón, de once, hasta los 3.200 rs. y otras once hasta los 6.400 rs.; la cúspide, por último, la constituyen seis, de las que cuatro se sitúan entre los $6.400 \mathrm{rs}$. y los $13.000 \mathrm{rs}$. y dos, por encima de ellos y hasta los 24.000 rs. (cuyos poseedores ya conocemos, por cierto). De este modo, respecto a aquella media de 1.647 rs., el 73'5\% (es decir,setenta y ocho bibliotecas) queda por debajo y más de la mitad de estas por debajo, incluso, del $50 \%$ de esa media (es decir bibliotecas de menos de $800 \mathrm{rs}$.). Lo que estas cifras parecen sugerir, es que para hablar de bibliotecas, con algún sentido significativo, deberemos tomar en consideración, solamente, los grupos de libros valorados a partir de 200 rs. o, siendo muy generosos, de 100 rs. En efecto, los 200 rs. nos garantizan, en promedio, entre 15 y 25 libros; menos de 100 rs. significarian, con toda probabilidad, entre 5 y 15 libros, con el «peligro» de que algunos breviarios, libros de horas $\mathbf{u}$ oficios litúrgicos constituyan todo el contenido. Naturalmente, sólo un vaciado sistemático de las 110 colecciones nos darían una confirmación de tal hipótesis, pero no parece éste el momento adecuado para efectuarlo (10).

Por razones de espacio nos asomaremos sólo a dos de estas bibliotecas, pequeñas, para examinar su contenido: la de D.José Zurita y la de D.Manuel González. Los 21 títulos de la primera son éstos: tres «Summas», la de Toledo, la de Cruz y la de Enriquez («Henriques»); dos catecismos, el «romano» y el «de Eusebio»; los «Ejercicios» del P. Rodríguez; dos de jurisprudencia, los «Instituta» de Justiniano y de Brocoltin; tres libros de confesores, el de Estella, un «Escrutinio de sacerdotes» anónimo y el «De sacerdotes» de Molina; dos libros laicos, las «Empresas» de Saavedra Fajardo y el «Vocabulario» de Nebrija; los otros ocho pertenecen al ámbito «devoto»: tres «vidas» la del Padre Contreras, la de la Rvda. Madre Antigua y la de la «Madre Trinidad; unos «Milagros del Rosario» y un «Hortulus marianus» junto a una «Exposición de los salmos de María»; el «libro de las fiestas de San Fernando» y una «Regula cleri atributio ad coelum», anónimo, además de una «Primacia de esta Santa Iglesia (de Sevilla)», que es una apología respecto a la de Toledo (11). Como puede apreciarse una «biblioteca» humilde, con algunas pinceladas de devoción mariana, las «suficientes» literaturas doctrinal, jurídica y moral, "profesionales» y algún «clásico» irremediable, como esas vidas del P. Fernando de Contreras y de la venerable Sor $\mathrm{M}^{\mathrm{a}}$ de la Antigua (autora también, renombrada, de unos 
«Desengaños de religiosas y de almas que tratan de la virtud»), que rara vez faltan en los fondos devocionales de cualquier conjunto de libros inventariado.

La segunda, la de D.Manuel González distribuye así sus 37 títulos (que, por cierto, reúnen 55 tomos en total): «Derecho civil y canónico» (8 tomos); «Super Instituta», de Pichardo ( 2 tomos); «Sobre las Decretales», de Balboa (2 tomos) e idéntico título de Graña (3 tomos); otro «Super Instituta» de Binio y un «Instituta Civilia» sin autor; un «Arte Legal» de Bermudez; «Pandectas Civiles» (2 tomos) y un «Vocabulario utriusque juris»; una buena colección jurídica con grandes tomos «in folio» aunque sin exagerar en la acumulación, a más que tanto las Pandectas como el Vocabulario jurídico son evidentes epítomes, puesto que son libros «en octavo». La filosofía y la teología están representadas por sendas «Summa», la de Ledesma y un «De Sacramentis» de Frias (la primera en folio y la segunda en cuarto); podríamos añadirle el «De Sacerdotibus» de Molina y dos tratados morales de Navarro, el «De restitutione» (en dos tomos en cuarto) y un «Manual». El segmento devocional tiene un tono ligeramente distinto a la biblioteca anterior, solo hay una vida de beato, la del Siervo de Dios «Gregorio López» y en cambio aparecen otras obras de diverso tono: un «Duelo espiritual» de Ronquillo y unos «Triunfos de Jesús y glorias de María» de Braones (dos libros distin-tos en realidad), junto a unos «Trabajos de Jesús, $2^{\mathrm{a}}$ parte» y los bastante frecuentes «Santos de Sevilla» (con toda probabilidad de Quintana Dueñas); luego aspectos «técnicos» de su profesión, como un «Arte del canto llano», la «Regla de coro de la Iglesia de Sevilla», los «Oficios de Semana Santa» (tiene tres) y «Oficio del Corpus», junto a unos «Breviarios» (en 4 tomos), un «Diurno» y unas «Horas de Ntra. Señora»; tres libros de literatura laica: el «Parnaso» de Quevedo (es decir, su obra poética) y las «Obras» de Quevedo (en prosa), junto al «De beneficiis» de Séneca, en romance; la «doctrina» está representada no por catecismos sino por la «Doctrina cristiana» de Fr. Luis de Granada (en realidad, el tomo VII de algunas ediciones de sus Obras que contiene la explicación de la doctrina cristiana) y la curiosidad histórico-festiva por unas «Honras de Sevilla a la reina $\mathrm{D}^{\mathrm{a}}$ María Luisa de Borbón» sin autor. Para concluir dos anotaciones más de difícil identificación: un «Alma nodi indisolubilis» (de cierta entidad puesto que en cuarto vale $20 \mathrm{rs}$.) sin otra indicación y dos tomos «manuscritos» con el título general de «Artes de materias» que recuerda a notas de comentarios escolásticos y que, seguramente por la encuadernación, valen 10 rs (12).

Vamos a retomar ahora los objetos de decoración o «artísticos» (con exclusión de los «oratorios» privados). Constituyen tales objetos la segunda rúbrica a la que íbamos a responsabilizar del perfil peculiar y distintivo del grupo. Para empezar sabemos que son 119 los inventarios que consignan «obras de arte» por un valor total de 265.489 rs. lo que en principio nos avisa que el gasto que estos objetos representan, en promedio, parece más fuerte que el de los libros aunque de muy similar frecuencia; concretamente frente a la «inversión» media de 1.647 rs. en libros, la de los objetos artísticos se eleva hasta los 2.231 rs. Al igual que en aquéllos, el recorrido de diversidad es enorme; nos movemos entre los 4 rs. del que menos tiene y los 18.535 rs. del que más; en medio, toda 
una escala cuyo pormenor es el siguiente: con valores inferiores a $100 \mathrm{rs}$, siete inventarios; entre 100-500 rs, veinticuatro; entre 500-1.000 rs, diecinueve; entre $1-2.000$ rs., treinta y uno; entre $2-4.000$ rs., veinte; entre $4-6.000$ rs., tres; entre 6-8.000 rs, cinco; entre 8-10.000 rs, tres y entre 10-12.000 rs, tres (conviene recordar que en esta escala no están incluidos ni el primero ni el último a los que aludimos ya). Semejante orden establece (ya lo hacía en los libros) que el $71 \%$ de estos inventarios queda por debajo del valor medio aritmético.

¿Qué contiene esta rúbrica?. Generalmente pinturas (lienzos, láminas y grabados); con menor frecuencia algunas imágenes y algún instrumento musical; más raramente algún pequeño «retablo». Al igual que hicimos con los libros, vamos a aproximarnos a unos pocos ejemplos que puedan resultar esclarecedores sobre todo respecto a la abundancia y variedad. Comenzaremos con el de los 4 rs.; se trata de D.Francisco Solís Infante, un presbítero y esos reales corresponden a «una lámina». El siguiente escalón, dando un salto «relativo», puede representarlo un racionero de la catedral, D. Francisco Félix Iribarri, que posee una imagen de 160 rs. y dos lienzos, valorados en 82 rs.; en total, 242 rs. Más o menos en el mismo nivel aunque con distinta estilística se mueve D.Sebastián Arias, presbítero administrador del Hospital Real de los Inocentes: dos «cuadritos», dos «lienzos», nueve «laminas» y doce «países» (paisajes generalmente y muy comunes) que alcanzan, en conjunto, los $306 \mathrm{rs}$. Un poco más alto se sitúa el canónigo D. José Rodríguez Bravo: sus 159 «estampas» valen 162 rs. y sus 26 «láminas» 156 rs. (así sabemos la diferencia de valor, de simple a cuádruple, entre unas y otras); una «escultura» $150 \mathrm{rs}$. y dos «cuadros» 62 rs.; en total, 464 rs. El presbítero veintenero D.Francisco Bernal de Estrada alcanza los 1.000 rs. con sus 12 «cuadros»,31 «láminas», 26 «paises» y una «escultura». D. Adrián Elossu, presbítero y maestro de ceremonias de la Catedral sube hasta los 2.132 rs. distribuidos así: 16 «cuadros» (378 rs), 15 «lienzos» (346 rs), 11 «mapas» (186 rs), dos «láminas» (225 rs), cinco «esculturas» (970 rs), un «relicario» (15 rs) y dos «sellos» (12 rs). Cuando saltamos a palabras mayores en este apartado, encontramos, por ejemplo, a D. Pedro Bernabé de Salinas, canónigo, con obras de arte por valor de 8.017 rs. que constituyen ya una muestra rica y variada: sus 42 cuadros son de cierta entidad ( $\ll$ dos varas de alto, o vara y media por vara y media de ancho o dos varas y tercia») y su valor oscila entre los 100 y los 660 rs. cada uno. El más caro es «del nacimiento de nuestro señor» («bara de alto y bara y media de ancho», tasado en 660 rs. acompañado de un nazareno, «Cristo con la cruz al hombro» ( $\ll$ dos baras y media de ancho y bara y media de alto»), valorado en 550 rs. y un «Señor San Pedro, dos baras de alto y bara y tercia de ancho») de 520 rs., todos ellos con sus molduras doradas o doradas y negras. Tiene además cinco bodegones: tres «fruteros» (de a tres cuartos de largo y media bara de ancho») en 420 rs. y dos «floreros» («dos baras de alto y bara de ancho») en 250 rs., todos naturalmente con sus marcos dorados. Tiene, por supuesto, un «Pays» (de dos varas y un tercio por una vara y cuarto) que vale 250 rs. y cinco láminas de cobre (dos de ellas con sus marcos de ébano, 30 rs. aunque otras dos,con molduras doradas, multiplican por cinco su valor, $150 \mathrm{rs}$.). La enumeración sería demasiado larga porque tiene también una imaginería variada y de valor: ocho tallas entre las que sobresalen 
dos Niños Jesús de alabastro con peana de ébano (340 rs), un Santo Cristo «con peana dorada y estofada y su cortina de gaza doble» (240 rs) o «una hechura de Nuestra Sra. de la Conzepción, de talla, con peana dorada y estofada, con su corona de plata» (287 rs). Pareciendo de amplio espectro, este inventario no constituye la cúspide. Veamos ahora, en valor muy similar (8.231 rs.), una dirección artística diferente; se trata de D.Domingo Damián de Olayzola, racionero «entero» de la Catedral y administrador del Hospital Real. Tiene seis lienzos de la vida de Cristo («de dos varas de largo con molduras negras y perfiles dorados») de «Juan Breugl» (Jan Brue-ghel, 1568-1625), a 375 rs. cada uno y otros seis con «los antecedentes de la vida de Cristo, de L.V.Herp» (Van Herp) a 300 rs. cada uno; tiene láminas, desde luego, pero de vara y media «poco mas...con sus molduras negras y doradas» a 240 rs. cada una; tiene, claro está, «países» pero de «más de dos varas de largo...con sus molduras negras y perfiles dorados», a 15 rs. cada uno; tiene una pintura de Ntra. Sra. de la Antigua «de medio cuerpo» de Domingo Martínez, «con moldura de cristales», que vale 750 rs. y una lámina «obalada, pequeña, del Silencio, con moldura dorada», del mismo autor, en $210 \mathrm{rs}$. En cuanto a la imaginería, tiene un retablo ( «tavernáculo de ébano embutido») con una imagen de la virgen de Copacabana, «con todo su adorno», en 750 rs o una imagen de Sto. Domingo «de escultura de media vara» de Cornejo (Pedro Cornejo) también en 750 rs.; o una «imagen de vestir de nuestra Señora de los Reyes, pequeñita, sin el adorno, por sola la escultura, 120 rs.»; también «un niño Jesús, con sus potencias de plata y vestidito y peana» en 150 rs. Y así todo. Pero, para concluir esta mirada a las colecciones de arte de nuestro clero, propondremos ahora el más importante inventario del que disponemos al respecto. Se trata de D. José Baeza y Mendoza, Chantre y canónigo de la Catedral, hermano del Dean y uno de cuyos albaceas fue el conde de Gerena, D.José Bucarelli y Ursua. Su patrimonio artístico es ciertamente impresionante; ahora que estamos ya familiarizados con los valores de tasación de tales obras podemos comprender, en su justa medida, lo que significan los $18.500 \mathrm{rs}$. largos en que se valora esta rúbrica (sin contar, desde luego, con el arte del oratorio, que suma casi otros 5.000 rs.). Adentrémonos, pues, en esta colección. Su cuerpo fundamental lo constituyen 39 lienzos, por un valor de 13.695 rs.; para comprender con juzteza esta cantidad conviene advertir que entre ellos existe: «un lienzo de la Asumpción de Nra. Señora, de tres varas poco mas de alto y dos varas poco mas de ancho, con su moldura de juguete dorada, original de Carlos Maratt» (C.Maratta, 1625-1713), valorado en 3.300 rs; otro de Santa Teresa de Jesús, de medida casi similar, «original de Juan de Valdés» (J. Valdés Leal, 1622-1690) tasado en 2.200 rs.; un Santo Tomás Apostol, «de dos varas poco mas de largo y vara y media de ancho, con su moldura de talla en bruto, original del $\mathrm{Cav}^{\circ}$ Mathias» (el caballero de la orden de Malta M.Preti, 1613-1699), en 1.500 rs.; un Adán y Eva de Juan del Castillo (1584?-1650), «de dos varas y media de alto y dos varas escasas de ancho...con su moldura en bruto» y que se tasa en 1.000 rs; dos lienzos de Herrera el Viejo, de medidas similares al anterior y representando uno a Job y el otro a Cristo despidiéndose de los Apóstoles, valorados en 1.500 reales ambos; un tercero, del mismo autor, con la Resurrección de Lázaro y medidas más reducidas que se tasa en 200 rs así como «una lámina de un Ecce Homo, de tres cuartas de alto» del propio Herrera 
el Viejo, en 100 rs.; otro lienzo de Sebastián de Llanos y Valdés (1605 ?-1677), «del señor San Geronimo, de dos varas de largo y una y tercia de ancho, con su marco dorado», en 600 rs. y una «lamina en cobre (La adoración de los Reyes) del mismo autor en 90 rs.; ocho «países, de dos varas y media de largo y dos varas menos tercia de ancho, con sus marcos dorados lizos, originales Italianos» que valen todos 1.200 rs: dos bodegones,»de vara y cuarto de alto y dos varas menos quarta de ancho», de Pedro Camprobin (1605-1674) en 90 rs.; un Lucas Valdés (1671-1725), apaisado («La negación de San Pedro,de dos varas de largo y vara y media de alto, con moldura dorada antigua) en 200 rs.; dos «países» de Ignacio Iriarte (1621-1685), ambos en 50 rs.; dos láminas representando a San Francisco y San Antonio, iguales, de Bazan, en 200 rs. y un lienzo «del Nacimiento...sin moldura» del mismo autor en 550 rs... Y así hasta 39 lienzos, 17 láminas y 15 países. En cuanto a sus siete imágenes (de las que nunca se indica el autor) sobresalen «una efigie de nuestro señor crucificado, de piedra, con la cruz de alabastro y remates dorados y peana de madera en su caja de madera pintada sobredorado, forrada por dentro en terciopelo negro» $(750 \mathrm{rs}$.), otra «de un Señor crucificado, de marfil, en su cruz de ébano con su sitial de damasco carmesí guarnesido con galón de plata con flecos de lo mismo en el dosel y dos laminitas a los lados una de Nra. Señora con su marco de ébano y otra un Agnus con su moldurita de cristales» ( 300 rs.) o un nuevo crucifijo de marfil «en su cruz de carey, en un tabernáculo de madera negra (150 rs.) o también esas «dos cabezas de barro, un Ecce Homo y Dolorosa en sus urnas y vidrieras» (240 rs.) (13).

Como ha podido comprobarse,en los niveles más altos encontramos una abundancia y variedad que ronda el coleccionismo, que da entrada a pintura italiana o flamenca (que, en los mejores casos, puede, incluso, estar «a la última") o que aprovecha el pretexto devocional para incluir pequeñas joyas de marfil, plata y ébano. Se transparenta, igualmente, en estos casos un gusto que se permite tímidas incursiones en la pintura no religiosa: además de los «bodegones» y los «países», de uso común, hay retratos (D. José Baeza y Mendoza tiene ocho «de diferentes obispos y doctores»), mitología (el mismo tiene «una lámina de una fábula»), «un lienzo...retrato de un borracho» $\mathrm{y}$ «dos lienzos de dos Philosofos», ambos en el inventario estrella de Baeza; en el de D.Pedro Bernabé aparece «una pintura ridícula» y varios «trampatojos»: «dos lienzos,fingidas dos tablas» $\mathrm{y}$ «una tabla fingida un lienzo».

A pesar del indudable atractivo de esta rúbrica del arte y la decoración deberemos abandonarla ahora en aras de la brevedad y sensatez que la ocasión exigen y pasar a otros rincones de las casas clericales, tampoco desprovistos (sino todo lo contrario) de interés y seducción.

Ya advertimos que mobiliario, menaje y ropa no iban a constituir ahora motivo de atención preferente por considerar que no aportaban peculiaridades al grupo; a pesar de ello, no dejaremos de apuntar algunas muestras de estas rúbricas utilizando un rastreo, puramente indicativo, por distintos inventarios para obtener una especie de catálogo en el que aparecerán piezas excepcionales y otras normales pero que en conjunto nos darán una idea bastante aproximada 
de lo que podría encontrarse en las casas del clero. Bien entendido que tales catálogos no sugieren, por supuesto, que en todas ellas aparezca la totalidad de las piezas reseñadas, sino que de tales conjuntos deberá entenderse que, como en todo lo demás, hay un arco de gran amplitud entre la pobreza y la riqueza.

Respecto al mobiliario, por ejemplo, encontramos:mesas; si son de caoba redondas «con los pies torneados» estarán en los 90 rs., si de pino en los 12 rs.; para las sillas tendremos igualmente distintas calidades, las de vaqueta de moscovia (piel de vaca curtida) se valoran entre los 30 y los 80 rs. cada una, según su estado de conservación, las de «descanso», en cambio, no bajarán de 120 rs. y las silletas de paja, sin embargo, no valen más de un real; poltronas a 50 rs. y tarimas de pino para camas entre 15 y 25 rs.; los taburetes también oscilan con amplitud desde los 15 rs. que puede valer uno de rejilla hasta los 60 rs. si fueran de vaqueta de moscovia; un catre, bien es verdad que de «granadillo salomónico" se valora en 100 rs. pero una cama, excelente, de palo santo, con sus colgaduras de damasco acuchillado en oro vale $3.000 \mathrm{rs}$.; los reclinatorios si son de caoba 70 rs. y las papeleras si son «inglesas» 150 rs.; un buen armario «extranjero» 240 rs. y las arcas, de enorme variedad, si son grandes y de cedro 120 rs, pequeñas de lo mismo, 45 y si descendemos hasta las arquitas bastarán 6 rs.; los espejos son siempre muebles caros, con marco dorado no valdrán menos de $150 \mathrm{rs}$. y el mismo precio para los de marco de ébano, en cambio si el marco es de «moldura de peral teñido» bastarán 100 rs. Escritorios y bufetes constituyen los muebles más frecuentes; entre los primeros, los mejores, de ébano y marfil, están en 400 rs., de ébano solo, entre 250 y 300 rs y de carey y marfil, entre 300 y 320 rs.; en ellos será fácil encontrar escribanías, que si son de madera y marfil estarán en torno a los 45 rs. y si de «linaloe» (madera de áloe) en los $75 \mathrm{rs}$; en cuanto a los bufetes, si son de caoba con herrajes, pequeños, oscilarán entre 75 y 90 rs. pero si superan el metro y medio de largo, con las mismas calidades, subirán hasta los 600 rs. y 150 para los intermedios; bufetes de cedro «forrado en materia de moscovia», pequeños, andan por los $66 \mathrm{rs.} \mathrm{y} \mathrm{si}$ están pintados y decorados, aunque sean de pino al menos 135 rs; los llamados «bufetes de estrado» están en los 45 rs. a no ser que sean «de comer, con su cajón», en los que este valor se reduce a la mitad; un «bufetillo ovalado» no valdrá más de 24 rs. pero si es «gateado en nacar» subirá al menos hasta los 60 rs. Por último, las vitrinas, que si son grandes alcanzarán entre los 200 y los 220 rs., si son medianas en torno a los 150 rs. y si de caoba subirán hasta los 360 rs (14).

Una ojeada a las cocinas no resultará improcedente; allí encontraremos el menaje de la casa que, como es de esperar, nos ofrecerá el menudo patrimonio de uso diario y utilidad evidente. Aquí cada metal impone su precio y esa es la diferencia cualitativa que establece los niveles: el azofar (latón), el peltre, el cobre, el hierro. Fuera de él, la porcelana y la cerámica tienen igualmente sus perfiles de calidad. Simplificando, podríamos establecer una regla sencilla: el menaje caro viene dado por la abundancia de peltre y latón, de juegos de China y de grandes utensilios de hierro; luego, cada «lujo» constituye un salto 
cualitativo sobre estas bases. Un ejemplo simple ayudaría a comprender: cinco vasos de «venecia» solo valen seis rs., siete de «pedernal labrados a buril»,90 rs. $\mathrm{Al}$ movernos en valores pequeños cualquier excepcionalidad marca la diferencia. En esta línea encontraremos platos: de peltre (grandes a 10 rs. y chicos a 3 rs.) puede haber varias docenas (en general los inventarios importantes tienen una docena de grandes y dos o tres docenas de pequeños); pozillos (tazas pequeñas), de china, pintados o no, entre 2 y 4 rs. la pieza (suele haber, en los mejores casos, docena y media); la taza grande de idéntica calidad y procedencia a 6 rs. la pieza, pero tazas puede haberlas también de "Guadalajara» a 2 rs., de «venturina» (una piedra noble traslúcida con vetas doradas) a 3,75 rs. la pieza, de "Valencia» a 4rs. la docena o de «Génova», usada 4rs; teteras (entre 25 y 30 rs.). Vamos al metal: los velones, de metal (?), los grandes a 20 rs., los pequeños de azofar a 10-12 rs.; los peroles: de cobre a 24 rs., de azofar, chicos entre 15 y 20 rs., medianos entre 35 y 55 rs. y grandes entre 90 y 110 rs.; chocolateros: de cobre, los chicos entre 5 y 8 rs., los grandes entre 12 y 14 rs.; ollas, de cobre, las grandes a 45 rs. y las pequeñas a 30 rs.; torteras de cobre, muy grande con su tapadera a 100 rs., medianas a 45 rs. y chicas 15 rs.; sartenes de hierro a 9 rs. y anafres, también de hierro, desde 15 rs., las pequeñas, a 50 rs., las grandes; trevedes de hierro a 4 rs. el par pero si son muy grandes, como las de la colada, a 30 rs.; calderas de «colan» (lavado de ropa) de cobre a 120 rs. y de hierro a 45 rs.; almireces, con su mano, entre 18 y 35 rs; parrillas y asadores de hierro a 2 y 4 rs. Naturalmente la riqueza de cada casa se mide por el número de cualquiera de estos enseres y las variedades de tinajas, búcaros, lebrillos y otros recipientes o utensilios de menor cuantía, entre los que merecen destacarse las «bazias» grandes de azofar ( 55 rs.), los «braserillos» de azofar con ollita de cobre ( 26 rs.) o ese «peso de fierro» con balanzas de cobre y tres pesas de hierro (30 rs) o la «anisera con jarro blanco de Olanda» (240 rs.). La cantidad es el nivel; de dos platos de peltre a tres docenas va un buen trecho y de dos pozillos a tres docenas y media también.

Si nos asomamos ahora al ajuar doméstico tenemos tres grandes grupos: el correspondiente a la cama y su ornato, el de la mesa y el aseo y las colgaduras y alfombras. En el primer grupo lo más aparatoso que podemos encontrar es el apresto completo de una «cama de aparato» que incluye colgadura, seis u ocho cortinas, colcha, alfombrilla y cielo, todo eso puede estar en tomo a los 500 rs.; en niveles más modestos las colchas estarán en torno a los 30 rs., los cobertores en 15 rs., sobrecamas con sus rodapiés, si son de «borlón blanco felpado» superarán en poco los 100 rs. si por el contrario son de «lienzo vizcaino» no pasarán de 20 rs.; los colchones a 60 rs. en promedio y las almohadas variarán, de ser con encajes, entre 15 y 20 rs, a ser de bretaña, entre 4 y 8 rs: en cuanto a las sábanas, las hay de muy distintos tipos, las llamadas sencillas entre 30 y 40 rs., las guarnecidas de encajes en los 120 rs., en cambio las de lienzo entre 10 y 30 rs. y las llamadas «finas de viaje» en 25 rs. Pasemos a la mesa: los manteles estrechos con menos de tres varas, entre 5 y 15 rs., los anchos, de tres varas y media o más, entre 10 y 20 rs. y los de Galicia a 9 rs.; las servilletas, «ordinarias», a 4 rs. pero si son de «Galicia», a 5 rs., en cambio las «alemánicas» a un real (bien es verdad que muy usadas) y las «de la Sierra» a dos rs.; los tapetes grandes entre 
30 y 40 rs.; por lo que se refiere a las toallas, el máximo serán las de seda «con soles de oro» entre 90 y 100 rs. pero no hay que llegar a tanto porque, las de «olan con encajes» valen exactamente la mitad, las «buenas, con soles» no suben de 12 rs. y las «medianas» no pasarán de 6 rs. aunque tengan «rapasejos» (fleco liso y sin labor particular). El capítulo de las colgaduras y alfombras tiene una rica variedad: podemos empezar con el género más espectacular que son las «colgaduras de sala», siendo de terciopelo damasco carmesí, con su fleco de oro y cenefa de lo mismo y con no menos de once paños, pueden costar la pequeña fortuna de 5.200 ó 5.500 rs.; más baratas pero siempre en alto nivel están las tapicerías, una de siete paños de 3,5 varas cuadradas estará en los 3.000 rs., pero también se pueden utilizar unos paramentos de paños, mucho más modestos aunque tengan «su águila», a 50 rs. unidad. Las cortinas recorren una variedad casi infinita: las hay de lienzo, buenas, a 15 rs., las grandes a 30 rs.; si son de crudo, las grandes a 18 rs. y las pequeñas a 12 rs.; si de tafetán carmesí, las de cinco paños a 62 rs., las de tres a 38 rs. y las de dos a 30 rs.; de bayeta «tinta en grana» a 30 rs. las grandes y 15 rs. las chicas; de tafetán celeste con cenefas, a 20 rs. unidad. Por su parte, para cubrir el suelo podemos usar o una buena alfombra de tres varas y media por dos y media, en 120 rs. o bien esteras que si son de esparto oscilarán, según tamaño, entre 10 y 20 rs. la unidad pero si son de junco blanco y encarnado se moverán entre los 100 y los 200 rs.

Por lo que respecta a la ropa personal podemos intentar, igualmente, un muestreo ilustrativo. En primer lugar la ropa eclesiástica: encontramos sotanas (de «tercianela de seda» a 120 rs., de «amul» (?) a 200 rs); capas (de paño fino a 120 rs., de paño usada a 40 rs. y de «burato de seda» a 180 rs); manteos (de tafetán a 75 rs., de burato de seda entre 140 y 200 rs., de burato de lana 60 rs., de bayeta 45 rs. y de paño 200 rs.; el capitular con muceta entre 120 y 200 rs.); mucetas solas 50 rs. y sobreropa (de damasco 120 rs. y de paño 150 rs.); sombreros (de vicuña $37 \mathrm{rs}$. y de castor $30 \mathrm{rs}$.) y borlas de sombrero a $10 \mathrm{rs}$. La ropa litúrgica es otra cosa: albas (de holan con encajes de Bruselas 240 rs.; de bretaña 75 rs.); cíngulos (de tela, 60 rs., de cinta de raso, 15 rs.); amitos (bordados 60 rs. y de estopilla 24 rs); sobrepelliz o roquete (de holan sin mangas entre 50-60 rs; con mangas, 120 rs.; de holan clarín, 90 rs.); ternos (una casulla y dos dalmáticas): de tela carmesí con galón de oro, 900 rs., de tela blanca bordada 1.000 rs., de lana blanca vieja 120 rs.; solo casulla de tela roja con estola y manípulo 75 rs., de tafetán 75 rs. y de tela blanca 180 rs. Por último ropa digamos civil: casacas (de tafetán doble, 70 rs., de pelo de camello 100 rs., bordadas en oro y forradas en raso 240 rs.); capotes (de pelo de camello forrado en estameña y con vueltas de felpa 330 rs.); ropillas -vestidura corta sin mangas que se pone sobre el jubón- (solo de tafetán 12 rs., de paño 15 rs., de damasco 45 rs.); calzones (de brabante, entre 12-15 rs. y los usados a 5 rs); camisas (con mangas de estopilla a $21 \mathrm{rs.}$ ); valonas (de encajes a $100 \mathrm{rs.);} \mathrm{camisones} \mathrm{(de} 18$ a 25 rs.); batas (de damasco, entre 150-180 rs.); calcetas y escarpines (2,5 rs. el par); medias (de seda, sin estrenar, 37 rs. el par y usadas, 22 rs.).

Para concluir con esta mirada de diablo cojuelo a los interiores de nuestras casas clericales y como habíamos prometido, dos vistazos rápidos a las dos 
puntas de las posesiones domésticas: la plata labrada por arriba y las humildes despensas por abajo.

Como ya es notorio, la plata (en general y en Sevilla en particular) constituye el «gesto» de riqueza casi imprescindible y, de una forma u otra y casi siempre «en la mesa», no deja de estar en cada inventario a partir de un nivel económico; incluso no muy alto (no olvidemos que el $63 \%$ de los inventarios clericales tienen plata), de modo que el refrancillo popular de la época, «Un pellizco de plata aún si to roe la rata», parece avalar una realidad bastante generalizada. La media de valor entre esos inventarios que la poseen es bastante alta, $6.091 \mathrm{rs}$. aunque, una vez más, las distancias entre los «pobres» y los «ricos» es abismal. El mínimo tiene 13 rs., el máximo, casi 58.000 rs. Entre ambos polos la estratificación acostumbrada. Prescindiendo de tres que no la valoran, el $9 \%$ de los que lo hacen tiene menos de 100 rs.; el $29 \%$ entre 100 y 1.000 rs. y el $30 \%$ entre $1-5.000$ rs, todos ellos,pues (68\%), por debajo de la media; el $8 \%$ entre $5-10.000$ rs.; el $10 \%$ entre $10-20.000$ rs.; otro $10 \%$ entre $20-40.000$ rs. y un $4 \%$ entre $40-60.000$ rs.

La realidad se perfila mejor aún cuando descubrimos que los 17 inventarios que más plata tienen acaparan el $82 \%$ del valor total de la plata inventariada y que, de ellos, los tres que están por encima de los 40.000 rs. acumulan, solos, el $26 \%$ de tal valor. De todos modos esta estratificación indica que la plata constituye, en cierta medida, un bien que tiende a mejorar los resultados de parámetros más sustanciales en la construcción piramidal del grupo, equiparando niveles con un índice de proximidad bastante más visible que entre otros parámetros: $38 \%$ de los inventarios con menos de 1.000 rs., $38 \%$ entre $1-10.000$ rs., $24 \%$ con mas de 10.000 rs.; sólo la cúspide sigue imponiendo su distancia espectacular.

Independientemente de la aritmética distributiva intentaremos ahora, como en otras ocasiones, establecer un muestreo significativo de objetos y valores. De un inventario modesto, aunque de buen pasar, puede servir de ejemplo el de D.Jerónimo Fuertes, cura del Hospital de San Lázaro; toda su plata esta compuesta por 30 cubiertos ( $1.674 \mathrm{rs}$.), un candelero ( $227 \mathrm{rs}$.), unas vinagreras (446 rs.), dos porta saleros ( 80 rs.) y una huevera ( 77 rs.); en total, 2.504 rs. Cosa muy diferente es el de D.Juan Agustín de Mora y Negro, racionero de la catedral, con sus 30.000 rs. inventariados. En él, sólo una «araña» ya vale 7.903 rs.; dos candelabros, 1.467 rs.; el juego de afeitar (jarro, palangana y jabonera), 1.501 rs.; seis fuentes, 4.351 rs.; una escribanía, 1.176 rs.; dos docenas y media de cubiertos, 3.607 rs.; un cucharón, 249 rs.; once cuchillos, 520 rs.; una palangana $736 \mathrm{rs}$.; cuatro salvillas (especie de fuente), $3.501 \mathrm{rs}$; cuatro «azafates» (bandeja en forma de cesta), 2.497 rs; tampoco faltará una escupidera (de escupir obviamente) en 390 rs., o una pileta de agua bendita en 433 rs., la palmatoria y los saleros que juntos valen 562 rs.; las hebillas, relicarios y cajitas no merecen la pena (en total solo valen 237 rs.), aunque sí las seis macerinas (plato para encajar la jícara de chocolate) que valen 1.170 rs.; el resto son menudencias como esos tres cocos de Indias (bolillas de plata para cuentas de rosario y similares) que valen $90 \mathrm{rs}$. o el bastón con puño de plata y su caja que se valoran 
en 136 rs. Por otros inventarios diferentes sabemos que existen, además, escribanías más caras, en 1.700 rs.; platillos de plata a casi 5.000 rs. la docena; jarros a 500 rs.; saleros grandes a 400 rs.; fuentes en 2.000 rs. y velones en otros 2.000; platos grandes que, incluso rotos, no bajan de 1.800 rs.; jícaras (piés y asas de plata) a 250 rs.la media docena; «vasos de camino» que en juego de cuatro están también en 250 rs. y tenedores y cucharas a 100 rs. la media docena de los primeros y 200 la de las segundas.

Después de estas cifras los alimentos de la despensa resultan casi ridículos; vienen aquí, sobre todo, por su valor testimonial de vidas reales y para aproximaciones etnológicas en su caso. Una despensa honestamente modesta (del canónigo Josế Rodríguez) no dejará de tener: seis jamones y medio valorados en 300 rs.; seis docenas de morcillas en 144 rs. y otras seis de chorizo en 180 rs, amen de dos arrobas de aceite para conservarlos en 64 rs.; 34,5 libras de chocolate en 306 rs., 69 libras de tocino en 130 rs. y 20 libras de manteca en 60 rs; termina esta despensa con el aceite del consumo normal, 16 arrobas tasadas en $176 \mathrm{rs}$ y 29 libras de peltre en $116 \mathrm{rs}$. El chocolate y el aceite parecen reservas muy comunes (hay quien tiene más de 30 kilos de chocolate por un valor de 500 rs. y casi 50 arrobas de aceite en tinajas en $1.500 \mathrm{rs}$.). En una despensa más modesta (la de D. Francisco Bernal, veintenero) el chocolate baja hasta 11 libras aunque se mantienen los seis jamones; el tocino baja hasta las 40 libras y el aceite a 7,5 arrobas, los chorizos y las morcillas solo son dos docenas aunque aparecen como novedades seis quesos ( $30 \mathrm{rs}$.), seis arrobas de miel que no se valoran y un tarro de lomo de puerco más tres libras de tabaco ordinario, sin valoración en ambos casos. Como queda de manifiesto, el corpus básico de las despensas lo constituye la economía del cerdo, probablemente incluso de elaboración casera, como lo demuestra el hecho de que aparezcan en ocasiones lebrillos de sangrar o grandes calderas de hierro para cocer las morcillas y gigantescas sartenes con sus trevedes para freir el chorizo o el lomo que después va a conservarse en aceite. Junto a estos productos, el chocolate constituye, no exactamente el toque exótico, que parece asumir el tabaco, sino la marca, en cierto modo literaria, del status clerical vinculada a la merienda canonical costumbrista. Punto y aparte merece el aceite, señor de las despensas y con harta probabilidad de las rentas beneficiales, esencia de la agricultura de la zona y demostración permanente de su versátil utilidad.

Despues de tanto curiosear fuerza será volver a las duras cifras para concluir, matizando, este retrato urgente y peculiar de unos clérigos sevillanos del largo setecientos y de sus habitats modestos, lujosos, apenas provistos, atiborrados, con algunas estampas, con verdaderas pinacotecas, con dos breviarios,con centenares de libros....como ya dijimos, clérigos de carne, hueso y pescuezo.

\section{4.-Una matización socioprofesional del grupo.}

Con todos los riesgos que puede comportar una desagregación motivada del conjunto clerical que nos ocupa, también podría resultar eficaz una comprobación, siquiera sea numérica, de la hipótesis, plausible, de que las 
distancias que hemos venido observando en los niveles de vida del clero inventariado, tienen que ver decisivamente con su status profesional. En contra de lo que pudiera parecer, intuitivamente, el resultado no será tan claro que nos proponga la identificación automática entre cargo eclesiástico y nivel patrimonial; vamos a intentar, de todos modos, aproximarnos, aritméticamente, a esta complejidad, valorando, lo más finamente que podamos, las concordancias y discordancias que encontremos en ella. Como siempre, la forma básica de comprobación será el cuadro numérico que sigue:

Cuadro $n=4$

Estructura de los activos por subgrupos socioprofesionales

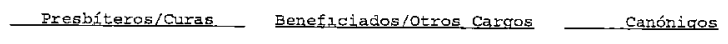

\begin{tabular}{|c|c|c|c|c|c|c|c|c|c|}
\hline Conceptos & Inv. & Valores & Total & $\operatorname{Inv}$ & Valores & sTotal & Inv. & Valores & Total \\
\hline Dinero en efectivo, & 31 & 489.304 & 25.40 & 22 & 771.108 & 30.80 & 22 & 738.978 & 26.10 \\
\hline Plata labrada & 30 & 52.894 & 2.70 & 27 & 129.165 & 5.16 & 32 & 360.095 & 12.70 \\
\hline Joyas & 21 & 79.959 & 4.10 & 21 & 80.611 & 3.20 & 13 & 96.980 & 3.40 \\
\hline Vales y acciones & 3 & 82.250 & 4.10 & 1 & 89.000 & 3.56 & - & ---- & --- \\
\hline Letras de cambio & 1 & 25.023 & 1.30 & - & $-\cdots-\ldots$ & --- & - & - - - & --- \\
\hline Deudas favorables & 22 & 424.462 & 21.80 & 23 & 818.979 & 32.70 & 16 & 119.447 & 15.90 \\
\hline Muebles & 60 & 183.249 & 9.50 & 41 & 123,305 & 4.90 & 35 & $192: 605$ & 6.90 \\
\hline Menaje & 44 & 23.016 & 1.20 & 35 & 20.900 & 0.80 & 34 & 65.325 & 2.30 \\
\hline Ropa familiar & 52 & 54.800 & 2.80 & 37 & 56.999 & 2.30 & 28 & 84.889 & 3.00 \\
\hline Ropa doméstica & 43 & 87.019 & 2.40 & 33 & 57.372 & 2.30 & 32 & 108.164 & 3.80 \\
\hline Objetos artísticos & 48 & 66.465 & 3.40 & 37 & 55.343 & 2.20 & 34 & 143.681 & 5.10 \\
\hline Bibliotecas & 14 & 59.223 & 3.00 & 34 & 51.908 & 2.07 & 32 & 70.027 & 2.50 \\
\hline Oratorios & 4 & 18.197 & 0.90 & 4 & 6.158 & 0.25 & 7 & 22.661 & 0.80 \\
\hline Canstiajes & 2 & 4.050 & 0.20 & 6 & 21.370 & 0.85 & 18 & 119.536 & 4.20 \\
\hline Despensa & 3 & 3.747 & 0.20 & 10 & 6.455 & 0.30 & 5 & 19.737 & 0.70 \\
\hline Prod.Agrícolas & 6 & 39.137 & 2.00 & 11 & 60.475 & 2.40 & 18 & 187.192 & 5.60 \\
\hline Ganado & 2. & 10.651 & 0.50 & 3 & $17.0 \pm 0$ & 0.70 & 8 & 91.238 & 3.20 \\
\hline Aperos & 3 & 21.036 & 1.10 & 1 & 1.560 & 0.10 & 6 & 25.602 & 0.90 \\
\hline Mercancías & 1 & 247.167 & 12.80 & 1 & 134.420 & 5.40 & 1 & 50.491 & 1.80 \\
\hline Utillaje & 2 & 182 & 0.00 & -- & $---n$ & $-\cdots$ & - & $-\cdots---$ & $-\cdots$ \\
\hline
\end{tabular}

2.-Bienés Inmiebles

\begin{tabular}{|c|c|c|c|c|c|c|c|c|c|}
\hline Tierras & 5 & 167.608 & 10.20 & 1 & 801 & 0.20 & 4 & 66.077 & 10.10 \\
\hline Ed]fic.Rúbtıcas & 1 & 6.816 & 0.40 & 1 & $500^{\prime}$ & 0.10 & 2 & 81.917 & 12.50 \\
\hline Inmuebles urbanos & 13 & 1.392 .563 & 85.00 & B & 211.700 & 56.15 & 8 & 484.951 & 74.00 \\
\hline Lacales negocios & 3 & 44.702 & 2.70 & . - & $-\ldots \ldots$ & ---- & - & $-\cdots--$ & $-\cdots--$ \\
\hline Censos/oficios venales & 3 & 27.370 & 1.70 & 2 & 164.000 & 43.50 & 1 & 22.000 & 3.40 \\
\hline Subtotal B. Trmuebles & 64 & 1.639 .058 & & 42 & 377.001 & & 36 & 654.945 & \\
\hline
\end{tabular}


El primer comentario debe referirse a las categorías. Hemos considerado esas tres que nos parecían las de mayores capacidades indiciarias: los curas simples y quienes sólo son atestiguados en el inventario como «presbíteros» (de hecho, como es obvio, presbíteros lo son todos pues es término que atañe al orden sacerdotal y no al status profesional); los beneficiados y prebendados más los presbíteros a los que se añade algún cargo de administración, tesorería, asesoría o inquisición; por último, los que el inventario atestigua como canónigos. Parece esta escala, de menor a mayor, un aceptable orden de expectativa de recursos y con ellos de «vidas» desiguales. Como era de esperar (y son indicios de la razonabilidad de la muestra) el número de inventarios sigue una escala inversa a la importancia social de los subgrupos: sesenta y cuatro para los simples curas; cuarenta y dos para los beneficiados y otros cargos y treinta y seis para el canonicato. A partir de ahí las diferencias significativas tienden a reforzarse entre los curas y los canónigos mientras se suavizan entre éstos y los beneficiados y es posible suponer que, en parte, ello se deba a problemas de terminología en el encabezamiento del inventario mismo. En efecto, un «prebendado» puede, perfectamente, ser miembro del capítulo catedralicio, en sus niveles más bajos, fuera de las dignidades importantes (deán, vicario, chantre, lectoral, penitenciario...) pero si en el inventario no se especifica su status capitular figurará en el grupo segundo y no en el de los canónigos.

En cualquier caso veamos qué diferencias parecen sugestivas en este pequeño arco de status. Las cifras totales del valor de los bienes muebles se nos ofrecen relativamente igualadas de modo que entre los esperadamente más pobres (los simples curas) y los supuestamente más ricos (los canónigos) «sólo» existe un $47 \%$ de superioridad en cuanto al valor global de tales bienes; la diferencia se reduce drásticamente entre los beneficiados y los canónigos hasta sólo un $12 \%$ a favor de estos últimos; entre los simples curas y los beneficiados la diferencia a favor de estos es solo del $33 \%$. No son diferencias escandalosas pero, de todos modos, parecen razonables: por cada cien reales de patrimonio muebles inventariado de los curas, los beneficiados disponen de 133 rs. y los canónigos de 147 rs. Con seguridad estas distancias se confirmarán y esclarecerán con los capitales medios. Si previamente hacemos intervenir los bienes inmuebles junto a los muebles las distancias se trivializan al principio: los «pobres» curas y los «ricos» canónigos casi se igualan (3.567.889 rs. para los primeros y 3.481 .593 rs. para los segundos); hay una explicación para ello, prescindiendo no sólo del hecho de que los primeros casi doblan en número de inventarios a los segundos sino también de que el bajo nivel de propiedad agraria de los canónigos puede sugerir bienes vinculados que el inventario no controla. La explicación más directa son las 46 casas que acumula un presbítero (como vimos en su momento); si eliminamos su valor (que era de más de $900.000 \mathrm{rs}$ ) como distorsionador del perfil de los bienes inmuebles de los simples curas,sus activos quedarían reducidos a 2.665.948 rs., lo que significa que el activo global de los canónigos (pese a la posible defectividad de sus propiedades agrícolas) volvería a estar un $30 \%$ por encima de ellos. Pero volvamos a los capitales medios. Sin retocar los números, el correspondiente a los simples curas se 
situaría en 55.748 rs. (por debajo, por tanto, del capital medio de la muestra que estaba, como se recordará, en 69.920 rs.), el de los beneficiados en 68.551 rs. (prácticamente igualando el capital medio del grupo) y el de los canónigos en 96.711 rs. (un $38 \%$ más alto que el medio y un $73,5 \%$ mayor que el de los simples curas). Si hacemos desaparecer el inventario que contiene esas 46 casas anómalas el capital medio de los curas bajaría hasta los 40.928 rs. y la distancia de los canónigos respecto a ellos se dispararía hasta un 136\%. Con casi el mismo número de inventarios que los canónigos el capital medio de los beneficiados está un $30 \%$ más bajo y un $23 \%$ más alto que el de los simples curas (con el inventario de las 46 casas incluidas) o, en caso de hacerlo desaparecer, un 67,5\%. La reorganización confirma y endurece el diagrama piramidal del status y vendría a decirnos ahora que, en promedio, por cada $100 \mathrm{rs}$. de capital medio de un simple cura, el beneficiado dispone de 123 rs. (sin eliminar el citado inventario ) o de 167,5 rs. (eliminándolo) y el canónigo de 173,5 rs. en el primer caso y de 236 rs.en el segundo. El esquema parece ahora mucho más verosímil $\mathrm{y}$ apunta a que (pese a las probables defectividades inmobiliarias del canonicato) entre un cura y un canónigo el nivel de vida medio va de simple a doble e incluso algo más. A partir de aquí casi cada rúbrica sustancial reproduce o aumenta esa distancia: si atendemos por ejemplo a lo que el valor medio de cada rúbrica representa para el conjunto de cada grupo y comparamos los resultados entre curas y canónigos obtendremos que, en el grupo capitular el valor del dinero es 2,7 veces más alto que el de los simples presbíteros; el de la plata, 12,5 veces; el de las joyas, lo multiplica por 2,2; el de los muebles, por 1,9; el del menaje por 5; el de la ropa personal por 2,8; el del ajuar por 4,2; el del arte por 3,8 y el de los libros por 2,1 . Si atribuimos el indice 100 a los valores medios aritméticos de cada rúbrica en el grupo de los simples curas, la distancia entre los grupos nos daría el cuadro siguiente:

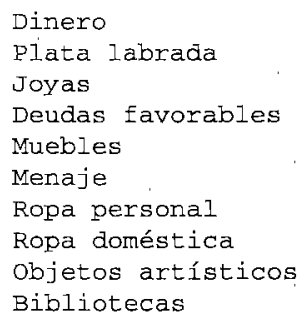

Presbíteros/
Curas
100
100
100
100
100
100
100
100
100
100

Beneficiados/
Otros cargos
240
372
154
296
102,5
138
158
186
127
134

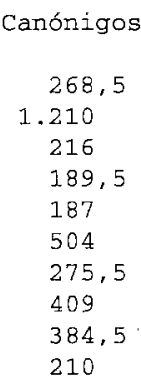

Nos parece que no hacen falta demasiados comentarios sobre el significado del status «profesional» en los niveles de vida de cada segmento clerical y sobre cómo se dibuja una pirámide muy rígida de punta capitular y base de curato con las «clases medias» beneficiales. Si agrupamos ahora para tener un modelo más simplificado, los valores medios de las rúbricas que tienen un cierto sentido en los niveles de vida tendremos el siguiente perfil: por lo que respecta a los valores que se refieren a riqueza neta (dinero, plata y joyas) por dada $100 \mathrm{rs}$. del curato, los beneficiados poseen 240 rs. y los canónigos 342 rs.; por lo que se atañe a la 
vida doméstica (muebles, menaje,ropa familiar y ajuar de la casa), por cada 100 rs. del curato, los beneficiados tienen 128 rs. y los canónigos 198 rs.; por último y por lo que se refiere a los bienes culturales (objetos de arte y libros), por cada 100 rs. de los simples curas, los beneficiados tienen 130 rs. y los canónigos 302 rs (15).

Hasta aquí, obligados por la mesura que un simple artículo propone (y que, con toda probabilidad, hemos superado ya con alguna amplitud), esta aproximación cuantificada a los niveles de vida del clero secular sevillano en ese largo siglo XVIII que se nos va hasta 1834. Los resultados nos parecen lo suficientemente verosímiles como para ser tenidos en cuenta y con capacidad indiciaria suficiente como para proponer, incluso, un primer modelo empírico de estructuración. Suponiendo que no tuviésemos más información del clero urbano de una gran ciudad catedralicia que la que esta muestra nos ofrece, sus resultados no parecen contradecir en absoluto (sino más bien lo contrario) las afirmaciones generales al respecto que pueden encontrarse en síntesis de la sociedad del Antiguo Régimen. Lo que aquí se conforma es un grupo que parece maquetar, miméticamente, el escalafón social general: una pequeña cúspide de riqueza no solo indiscutible sino con ciertos visos de espectacular; unos segmentos medios razonablemente extensos pero en modo alguno generalizados, de un nivel de vida holgado y sólido pero sin exageraciones no ya en lujos sino ni siquiera en confort notable; y una base que en número casi duplica al grupo medio y que con dificultad elude la pobreza sin paliativos. Cuando se desconcha este organigrama esquemático, aproximándonos con más ampliación (lupa cuantitativa y lupa cualitativa) al detalle de las fortunas constatables, lo que se configura es el abismo entre la riqueza sin paliativos y la pobreza evidente. La muestra clerical ofrece una cúspide de élites sociales sin discusión, que puede establecerse en torno al 16\% (y que acumula las tres cuartas partes del capital del grupo); una cola de pobreza rigurosa que afecta a uno de cada cuatro clérigos inventariados ( $26 \%$ del grupo con el $1,7 \%$ de su capital) y un denso segmento central con casi el $60 \%$ del grupo y el $23 \%$ del capital. Los datos sugieren, además que, en promedio, es la actividad «añadida», en forma de cargos o dignidades, la que va marcando el nivel de vida y el grosor del patrimonio. Algunos tópicos como los que se vislumbran en los refranes que hemos utilizado como encabezamiento de este trabajo, se disuelven con facilidad ente las cifras y se confirman, por contra, otras aproximaciones al grupo realizadas con distintas fuentes. En definitiva, un paso adelante para establecer la tendencia de representatividad sociológica del clero secular urbano...o, al menos, esa es nuestra opinión. 
NOTAS.

(1) Cfdo. Bernal Rodríguez, M., El hábito no hace al monje. Sevilla, 1994.

(2) Alvarez Santaló, L.C., y García-Baquero González, A.: «Estructura y funcionalidad del capital andaluz en vísperas de la primera industrialización» en Revista de Estudios Regionales, $\mathrm{n}^{\circ} 5$ (Málaga, 1980), pp. 101-133, de los mismos autores: «La nobleza titulada en Sevilla, 1700-1834», en Historia. Instituciones. Documentos, $\mathrm{n}^{\circ} 7$ (Sevilla, 1981), pp. 125-167; «El utillaje agrícola en la tierra de Sevilla, 1700-1834» en Archivo Hispalense, $\mathrm{n}^{\circ}$ 193-194 (Sevilla, 1981), pp. 235-267; «Los inventarios post mortem como fuente para la historia agraria del Antiguo Régimen", en Actas II Coloquios Historia de Andalucía. Andalucía Moderna. Córdoba, 1983, Vol. I, pp. 137-150; «Una aproximación al status socioeconómico del artesanado sevillano de fines del Antiguo Régimen», en $L$ ' ouvrier, la Bourgogne et la vie provinciale, parcours d' un historien. Casa de Velázquez, Madrid, 1994, pp. 91-106.

(3) Ventajas y desventajas, avisos y precauciones fueron exhaustivamente tratados, como se sabe, en La documentación notarial en la historia. Actas II Coloquio de Metodología Histórica Aplicada. 2 vols., Santiago de CompostelaSalamanca, 1984; cada vez que se publican estudios sobre la base, total o parcial, de esta documentación se reproducen las prudencias y los aquilatamientos; vid. por ejemplo Franch:Benavent, R: Crecimiento comercial y enriquecimiento burgués en la Valencia del siglo XVIII. Valencia, 1986; Morgado García, A.: Iglesia y sociedad en el Cádiz del siglo XVIII. Cádiz, 1989; Riqueza y sociedad en la Sevilla del siglo XVII. Sevilla, 1994; Rodríguez Vázquez, A.L.: Ricos y pobres; propiedad y vida privada en la Sevilla del siglo XVI. Sevilla, 1995; Catalá Sanz, J.A.: Rentas y patrimonios de la nobleza valenciana del siglo XVIII. Madrid, 1995.

(4) Ros, C. (dir), Historia de la Iglesia de Sevilla. Sevilla, 1992; Candau Chacón, M.L.: La carrera eclesiástica en el siglo XVIII. Modelos, cauces y formas de promoción en la Sevilla rural. Sevilla, 1993; de la misma autora: Los delitos y las penas en el mundo eclesiástico sevillano del siglo XVIII. Sevilla, 1993; y El clero rural de Sevilla en el siglo XVIII. Sevilla, 1994; en este último trabajo hay un capítulo (el $2^{\circ}$ de la segunda parte) dedicado a «los bienes temporales» pero la información que utiliza para los patrimonios procede de fuentes de inspección eclesiástica y no notarial aunque pueden ser útiles para calibrar al clero rural.

(5) Conviene advertir que todas estas cifras se refieren a capitales activos, independientemente del nivel de liquidez que ello represente y que se pondrá de manifiesto cuando hagamos intervenir los pasivos. En cualquier caso y por ahora baste señalar que los patrimonios que representan estos activos del clero estuvieron gravados con deudas que alcanzaron la cifra de 1.668 .107 reales de vellón ( $17 \%$ del valor patrimonial) y que luego tuvieron unos gastos post óbito que se elevaron a 195.433 reales ( $2 \%$ de los activos). En consecuencia los 
previsibles herederos de esta muestra sólo pudieron serlo de 8.065 .084 reales, una vez liquidados los bienes, si tal cosa sucedió.

(6) Por no remontarnos demasiado atrás, veamos dos muestras sencillas más recientes. En el prólogo a la obra de la prof. Candau ya citada (El clero rural de Sevilla...) A. Mestre afirma: «...no dejará de llamar la atención del lector menos especializado...las diferencias existentes entre los miembros del clericato. Porque si las élites sociales del clero (obispos, canónigos, párrocos) lograban pingües rentas, otros grupos, mucho más numerosos, sufrían las necesidades de las clases sociales menos dotadas. Era la jerarquía la que establecía el privilegio...»; Op. cit., pág. 14. Por su parte, J. Bravo Lozano, en su análisis del clero madrileño, afirma: «El desplazar la cuestión desde el terreno específico del clero al campo de la estructura social de Castilla, es una confesión de que el clero no tiene vida propia, ni criterios propios de selección y promoción de sus miembros, que el clero no es, en fin, más que un mero calco de la sociedad en su conjunto». Cfdo. «Cura rico-cura pobre. Notas sobre rentas eclesiásticas en el Madrid de fines del siglo XVII» en Martínez Ruiz, E., y Suárez Grimón (Eds.): Iglesia y Sociedad en el Antiguo Régimen. Las Palmas de Gran Canaria, 1994, pp. 129-139; la cita en pág. 133.

(7) Puede comprobarse en Barrio Gozalo, M.: Estudio socioeconómico de la Iglesia de Segovia en el siglo XVIII. Segovia, 1982; del mismo autor: «El bajo clero en la España del siglo XVIII. Estado de la cuestión, problemas y direcciones» en Actas del Coloquio Internacional Carlos III y su siglo. Madrid, 1990, Tomo I, pp. 793-805. Ahí se encontrarán informes episcopales y memoriales en los que se dice textualmente: «muchos clérigos, párrocos, beneficiados y capellanes, permanecen excomulgados por largo tiempo al no serles posible pagar la cantidad que les corresponde del subsidio y el excusado», o también, «se ven obligados a mendigar o a mezclarse en negocios ajenos a su estado para poder subsistir»; ambas citas en pp. 797 y 798. Bravo Lozano se refiere también a este fenómeno de la pobreza radical del clero: «...la pobreza es un fenómeno urbano, esencialmente urbano, incluso en el clero», op. cit., pág. 138.

(8) La presencia de importantes cantidades de dinero metálico se produce también al menos en dos de los cinco inventarios, todos capitulares, que comenta el prof. A. Morgado (cfdo.: Op. cit., pp. 112-113), aunque él no les concede ninguna significación. Aparecen igualmente en testamentos clericales e inventarios de Madrid y Santiago de Compostela. Respecto a los madrileños. Bravo Lozano no tiene ninguna duda sobre la actividad prestamista: «cura rico, convertido cuasi automáticamente en prestamista; cura rico; prestamista obligado a ser buen administrador...inversor y prestamista pero con atención especial a sus convecinos y paisanos...». Op. cit. pág. 129; respecto a los santiagueses, $O$. Rey Castelao dedica un epígrafe a las «memorias de deudas» y en su opinión el préstamo existe, desde luego, e incluso el préstamo bajo prenda, aunque no lo interpreta como negocio: «A nuestro entender, casi un un $65 \%$ de los deudores se reclutan en los sectores primario y secundario; labradores y 
artesanado urbano, sobre todo, que forman una auténtica nube en torno al clero medio e inferior. Como garantía de estos pequeños préstamos el clero santiagués dispone de innumerables piezas de plata o de elementos del ajuar...Es evidente que no se cobra ningún tipo de interés». Cfdo. «El clero urbano compostelano a fines del siglo XVII: mentalidades y hábitos culturales» en La historia social de Galicia en sus fuentes de protocolos. Santiago, 1981, pp. 495-519; la cita en pág. 505. También la detecta Barreiro Mallón en sus inventarios de clero santiagués del siglo XVIII aunque no le atribuye más significado que el ahorro "posible». Cfdo. «Las clases urbanas de Santiago en el siglo XVIII: definición de un estilo de vida y pensamiento» en La historia social de Galicia...pp. 449-494.

(9) Puede servir de ejemplo pormenorizado de las cantidades a las que nos estamos refiriendonos la siguiente anotación en el inventario de D. Manuel González de Aguilar y Rojas, canónigo: «6641 pesos escudos de plata, de a diez reales de plata. Tal cantidad se encontró en monedas de doblones de oro y en plata doble sevillana columnaria y mexicana y en reales de a dos reales sencillos $y$ en medios reales antiguos y en pesos nuevos de a doce reales. A esto se añaden 14.000 rs. en vellón de calderilla». En total casi 150.000 rs. de vellón.

(10) A. Morgado comenta 18 bibliotecas clericales gaditanas, genéricamente; aunque sin valoración económica, de modo que puede ser útil para comparar títulos y autores. Cfdo. Op. cit. pp. 46-52. Igualmente. L.C. Alvarez Santaló, «Librerías y bibliotecas en la Sevilla del siglo XVIII» en La documentación notarial y la historia...Vol. II, pp. 165-185; del mismo autor «Adoctrinamiento y devoción en las bibliotecas sevillanas del siglo XVIII» en Alvarez Santaló, Buxó y R. Becerra (Eds.): La religiosidad popular. Barcelona, 1989, Vol. II, pp. 21-46, asimismo en los trabajos ya citados Barreiro Mallón y Rey Castelao pueden encontrarse ejemplos pormenorizados.

(11) Los libros reconocidos entre los que se prestan a confusión son: Francisco de Toledo: Summa casuum...sive de instructione sacerdotum; Enrico Enríquez: Summa Theologia moralis; Juan Eusebio Nieremberg: Práctica del catecismo romano; Alonso Rodríguez: Ejercicios de perfección y virtudes cristianas; Diego de Estella: Obras; Anónimo: Memorial...de la Santa Iglesia metropolitana y patriarcal de Sevilla (Sevilla, 1722); Antonio de Molina: Instrucción de sacerdotes...; P. Espinosa de los Monteros: Vida y muerte del venerable sacerdote Fernando de Contreras...; Fr. Antonio de Lorea: La venerable madre sor María de la Stma. Trinidad...; Fr. Andrés de San Agustín: Vida exemplar...de soror María de la Antigua...; Joannes Rebello: Historia de los milagros del Rosario (tres partes); Fernando de la Torre Farfan: Fiestas de la Iglesia Metropolitana...al nuevo culto del Sr. Rey San Fernando.

(12) Los libros reconocidos entre los de dudosa atribución son: Antonio Pichardo Vinuesa: In tres priores institutionum...Justiniani...; Juan de Balboa de Mogrovejo: Lectiones...sive...relectiones ad titulos libri secundi decretalium; Francisco Bermúdez de Pedraza: Arte legal para estudiar la jurisprudencia; Pedro de Ledesma: Summa; Alfonso Frías y Zúñiga: De sacramentis novae 
legis; Martin de Azpilcueta (Dr. Navarro): Manual de confesores y penitentes; Fr. Juan Ronquillo: Duelo espiritual. Combate entre la carne y el espíritu...; Alonso Martín Braones: Epítome de los triunfos de Jesús y Epítome de las glorias de María (ambos en 500 octavas); Fr. Thomé de Jesús: Trabajos de Jesús (en dos partes); Lucio Anneo Séneca: Los libros de beneficiis...traducidos por P. Fernández Navarrete; hay por lo menos cinco autores distintos de vidas de Gregorio López: Alfonso Ramón, Francisco de Losa, Francisco Núñez de Avila, Juan López Reposo y Luis Muñoz; podría ser cualquiera de ellos.

(13) Pueden compararse estas colecciones con las que relaciona A. Morgado para Cádiz en las que también una destaca sobre todas las demás. Cfdo. Op. cit. pp. 52-54.

(14) Barreiro Mallón aunque sólo ofrece un inventario con valoraciones de conjunto se refiere, sin embargo, con mayor amplitud y extensión a otros mobiliarios y a plata sin valorar. Op. cit. pp. 455-460.

(15) Bravo Lozano parece coincidir, sin retícula cuantitativa, pero con su documentación testamentaria en las manos con nuestra apreciación: «En conjunto se puede pensar que aquellos curas que no han accedido a ningún beneficio, que sobreviven de alguna capellanía, que no están vinculados a ninguna parroquia, están condenados a ser pobres aunque no miserables...Curas pobres, por tanto, encontraremos en todos aquellos no protegidos por el sistema social ni la familia». Cfdo. Op. cit. pp. 137-138. 


\section{Patrimonio del Clero}

Distribución proporcional de los bienes muebles

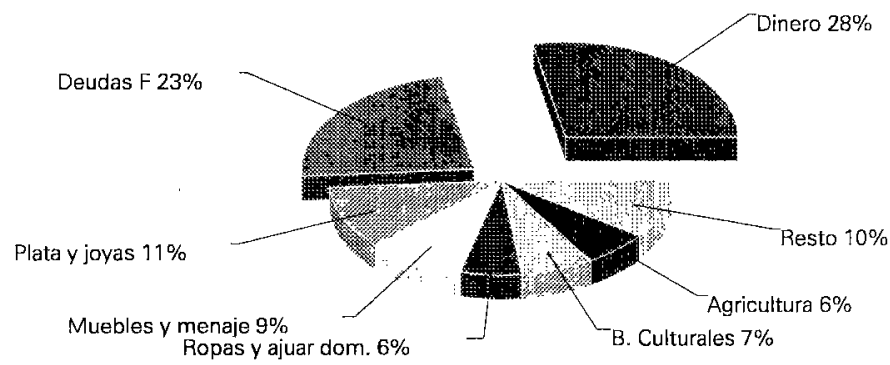

\section{Patrimonio del Clero}

Distribución proporcional de los bienes inmuebles

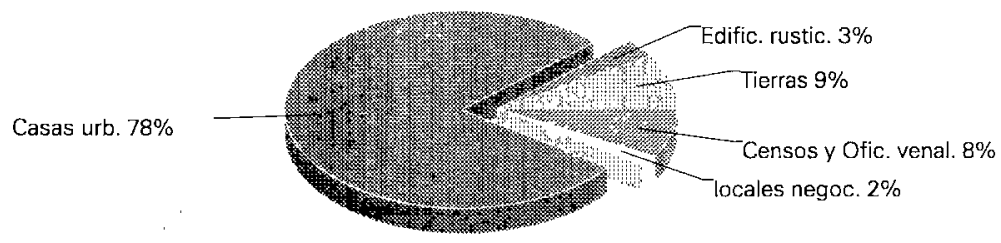

Patrimonio del Clero

Distribución de activos

Bienes muebles $73 \%$

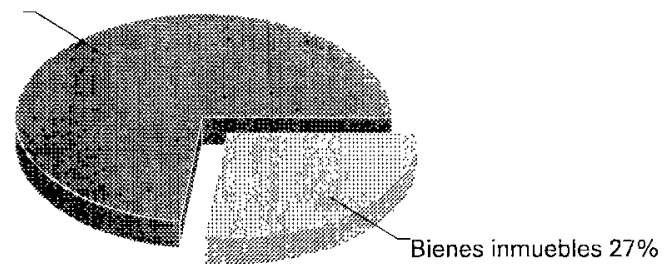


Relación entre $\mathrm{N}^{\circ}$ de Inventarios y volúmen de Capital Encuesta General

$20 \%-65 \%$

$37 \%-27 \%$

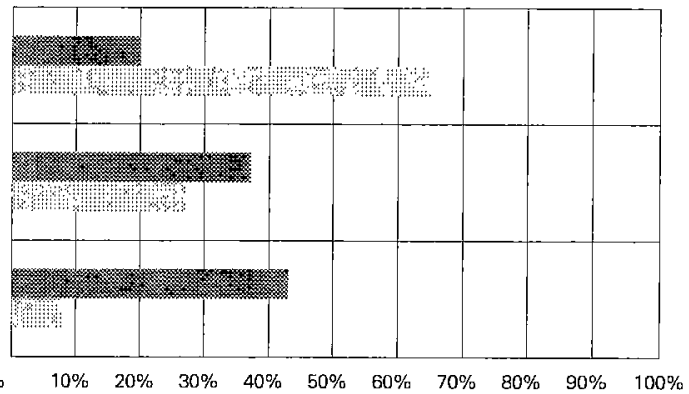

Inventarios

Capital

Relación entre $\mathrm{N}^{\circ}$ de Inventarios y volúmen de Capital Muestra clero

$16 \%-75 \%$

$58 \%-23 \%$

$26 \%-2 \%$

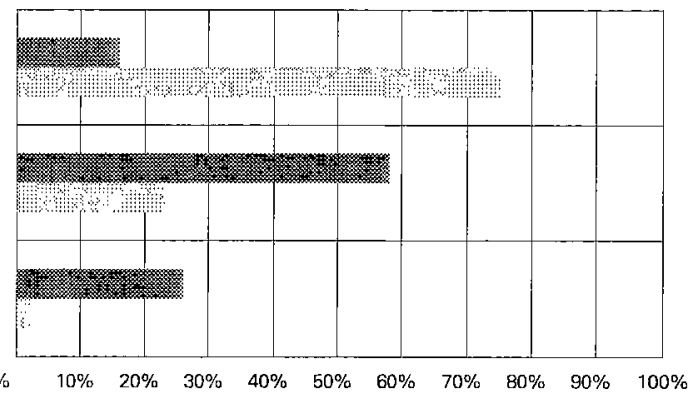

Inventarios

Capital 